\title{
العلاقة بين مؤشرات التخطيط الاستراتيجي والأداء الجامعي في جامعة علدن
}

\author{
" أسوان حمزة
}

تاريخ قبوله 2019/6/30

تاريخ تسلم البحث 2019/4/8

The Relationship Between the Strategic Planning Indicators and University Performance at University of Aden

\section{Aswan Hamza, University of Aden, Yeman.}

Abstract: The study aimed at investigating the relationship between the strategic planning indicators and university performance from graduate and postgraduate students' perspective at Aden University. To achieve this aim, an identification of the degrees of the availability of strategic planning indicators and university performance was developed in order to find out any significant differences between students' average response to the strategic planning indicators and university performance due to specialization and educational level variables. The study sample involved (144) stratified selected students. Two instruments were developed, the first for the strategic planning indicators, and the second for university performance. The results showed moderate degrees of availability of the strategic palnning indicators and university performance. Regarding specialization variable, there were differences in the first instrument, whole scale, along with its mission and goals subscales. Additionally, there were differences in the second instrument whole scale and its all subscales in favor of students of administration. Concerning the educational level variable, there were differences in mission and goals subscales, and the second instrument whole scale and its all subscales, in favor of postgraduate students. Regarding the interaction level interaction, there were differences in educational process subscale, in favor of post-graduate students of administration. The results also showed a strong positive correlation between the indicators of strategic planning and university performance.

(Keywords: Strategic Planning, University Performance, Strategic Goals, Post-graduate Students)

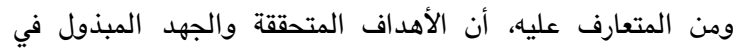

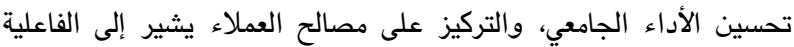

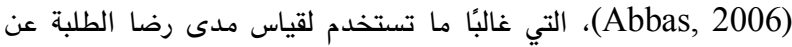

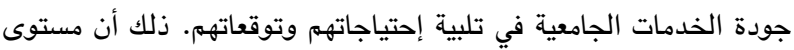

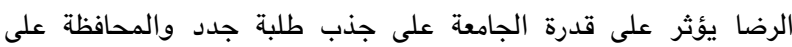

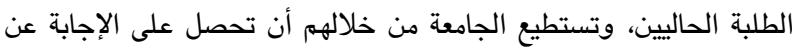

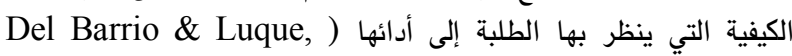

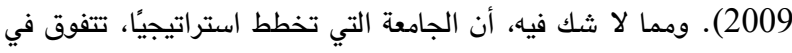

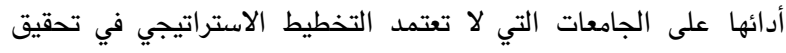

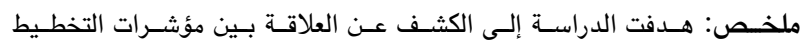

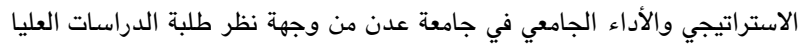

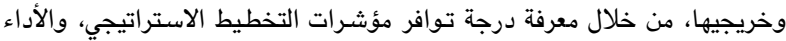

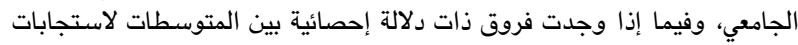

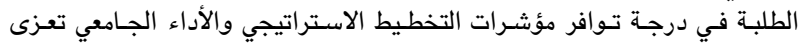

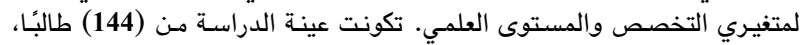

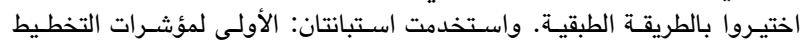

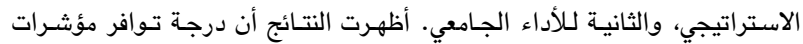

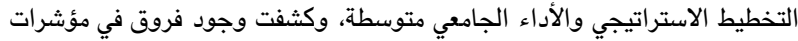

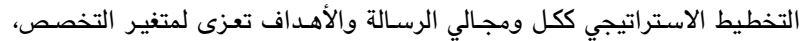

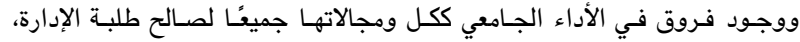

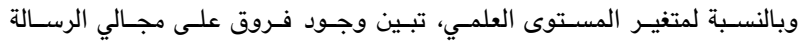

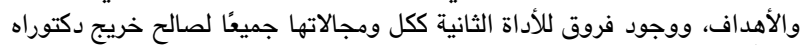

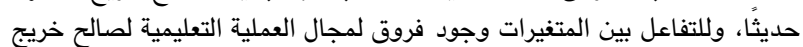

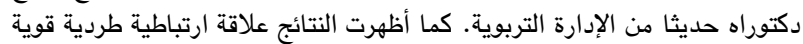
بين مؤشرات التخطيط الاستراتيجي والأداء الجامعي.

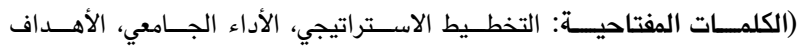
الإستراتيجبة، طلبة الدراسات العليات التيات العات

مقدمـة: يشهـد للجامعات بأنها مؤسسـات أكاديمية حيويـة، تمثل

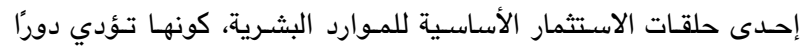

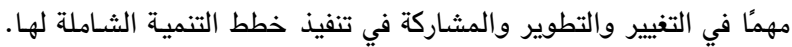

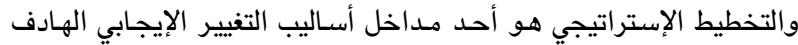

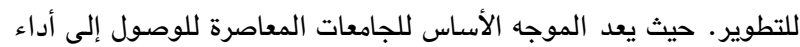

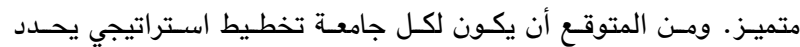

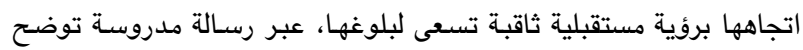

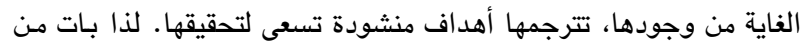
الأهمية بمكان فحص توافر مؤشرات التخطيط الاستراتيجي، لمعرفة فاعلية

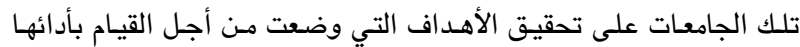

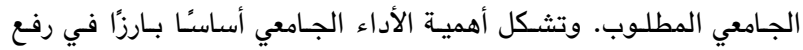

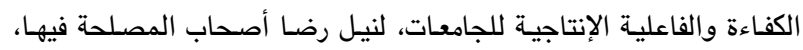

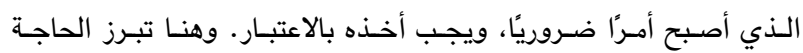

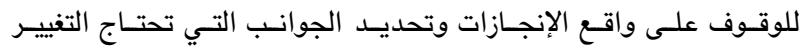

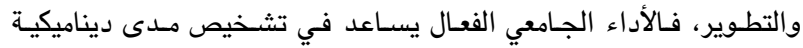

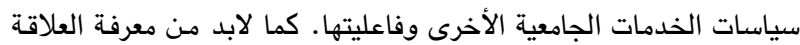
بين التخطيط الاستراتيجي والأداء الجامعي.

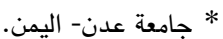
(C) حقوق الطبع محفوظة لجامعة اليرموك، اربد، الأردن. (C) 
القيم (Alaqeel \& Alhyary, 2014)، وقد لوحظ زيادة اهتمام المؤسسات التربوية بتدريس بعض المقررات ذات العلاقة بأخلاقيات

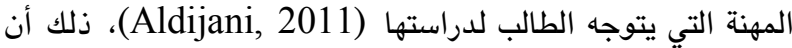
الطلبة قادمون من بيئات مختلفة بمفاهيم ومعتقدات متنوعة، فضلاً عن تأثرهم بأفكار قد تكون غير ملائمة لقيم ومبادئ البيئة الجامعية

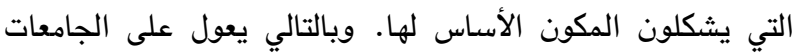

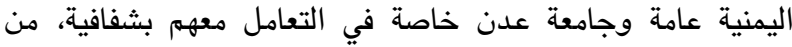

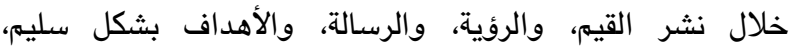
وإشراكهم في نشاطات تؤدي إلى فهمهم لها، بحيث يعيها ويتبناها أغلبيتهم. والثرا.

والرؤية هي الحالة المثالية التي ينبغي الوصول إليها، وتعكس

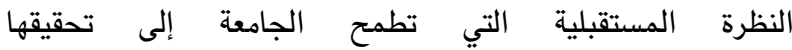

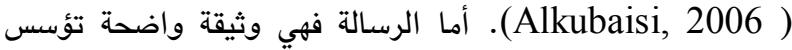

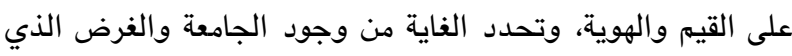

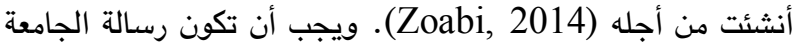

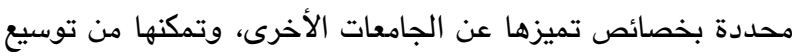
أنثطتها دون الحاجة إلى إعادة صياغتها (Rustam, 2004).

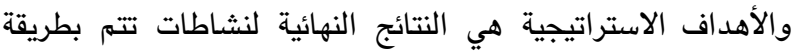

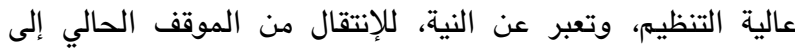

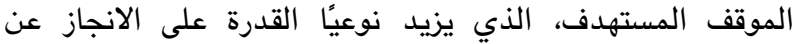

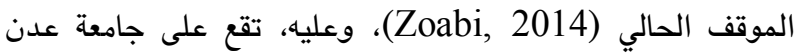
تحديدًا المسئولية المباشرة في تحقيق الأهداف التي تضمن أداء

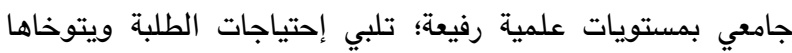

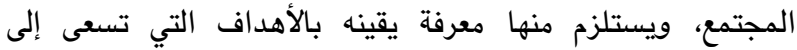

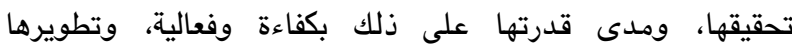

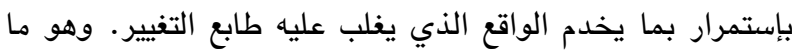
أشار إليه ويلين وهنجر (Wheelen, \& Hunger, 2004) بأن الأنان الإستراتيجية هي خطط وأنشطة المؤسسة التي يتم وضعها بطريقة

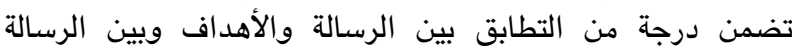
واليئة التي تعمل بها بكفاءة عالية وبصورة فعالة. والأداء هو درجة تقدم العمليات التي تحقق فيها المؤسسة أهدافها (Aldawi, 2010). والأداء الجامعي هو المحصلة النهائية

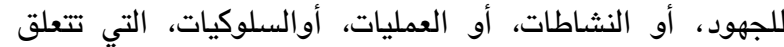

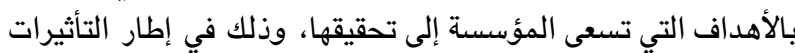

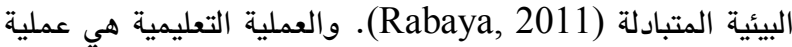

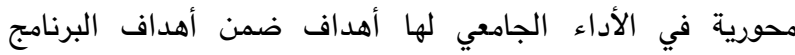
التعليمي ككل (Alabidi \& Alabadi, 2007). والبحث العلمي الادني هو مجموعة الجهود المنظمة التي تستخدم الأسلوب العلمي العيد العيد وقواعد الطريقة العلمية بهدف اكتشاف معارف جديدة تساعد في الأدي تحسين الأداء والحصول على جودة عالية للمخرجات والخدات الخدمات (Obaidat, Abdul-Haq \& Adas, 2004). ولذا يتطلب قياس درجة الأداء الجامعي وضع أسس موضوعية وعادلة لضمان تحسينه. ويشترط توافر أداء ملموس ومعمول لهاء به من من المستفيدين
والأداء الجامعي الجيد والمتناسب ومتطلبات العصر، هو نتاج

لتلك الجامعة التي لديها تخطيط استراتيجي (Zoabi, 2014)

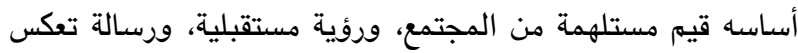

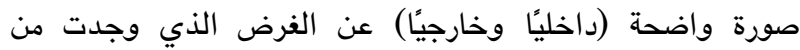

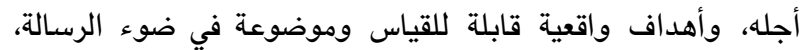
يمكن تحقيقها وفقا للقدرات والإمكانات المتاحة ( Cowburn, 2005). والجدير بالذكر هنا أن التخطيط الاستراتيجي من أجل الإنات التاني

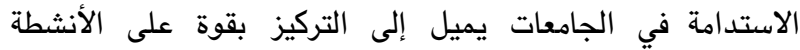
المتعلقة بأهداف تنفيذية كأنشطة بيئية على مستوى الييئة الداخلية والخارجية المعروفة للجامعة، ويأخذ في الاعتبار متفيراتها الداخلية

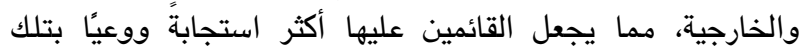

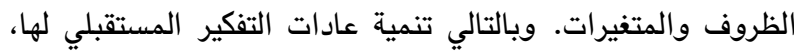
لأن تجاهل المسائل الداخلية والخارجية قد يقود إلى نتائج سلبية من خلال اتخاذ قرارات غير مجدية ( Bieler \& McKenzie, .(2017; Rustam, 2004

والتخطيط الاستراتيجي عملية تحليلية مستمرة لإختيار رؤية لمكانة مستقبلية تقوم على توقعات جميع المعنيين بها، ويمستويات الاتئية

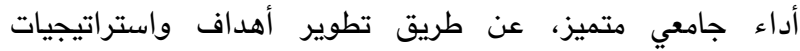
(Ghoneim, 2008; وسياسات، واتخاذ قرارات فعالة لتحقيقهات Druker, 1974) ملحة للمؤسسات، إن أرادت زيادة قدراتها التنافسية وتطوير أدائها.

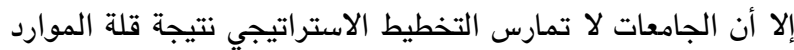

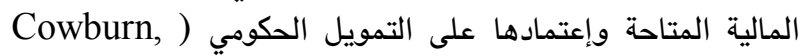

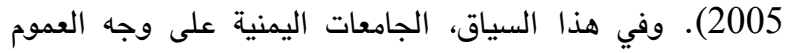

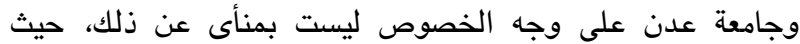

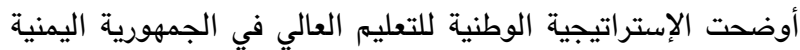

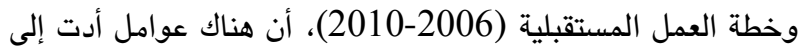
ضعف قدرة الجامعات اليمنية على استخدام مواردها استخدامًا

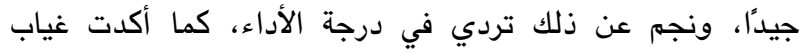

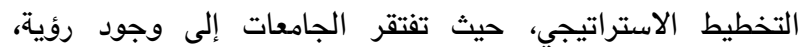

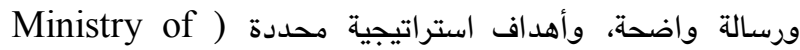
Higher Education and Scientific Research, 2006:

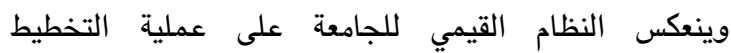

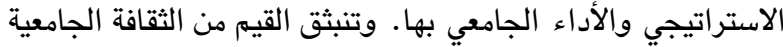

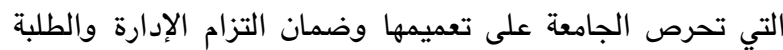

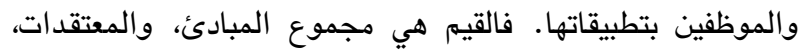

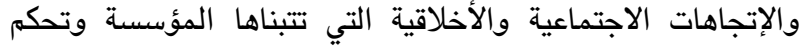
Alfayyad, ) سياستها وطريقة اتخاذ قراراتها وحل مشكلاتلاتهات الاتهات

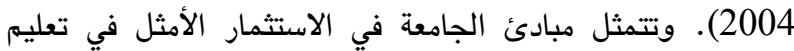

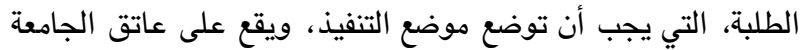

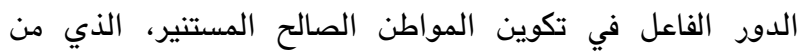
المفترض أن تتميز شخصيته بالسلوك الأخلاقي الذي توجها 
وعلى صعيد الدراسات المتعلقة بالجامعات اليمنية، له تحظ العلاقة بين التخطيط الاستراتيجي وجودة الأداء بالأهتمام المناسب.

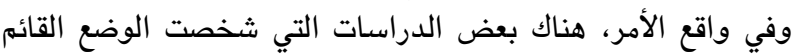

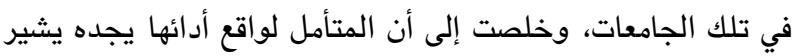

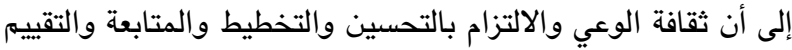

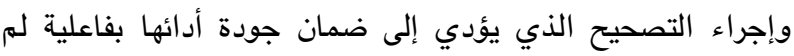

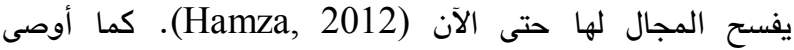
العبيدي (Alobeidi, 2004) الجامعات اليمنية أن تتبنى مدخل

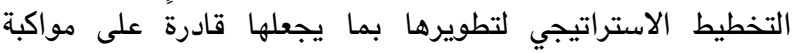
التغيرات البيئية المحيطة، وأن تعنى بالاستراتيجيات وآليات تنفيذها، وتحليل اليئتين الداخلية والخارجية لمعرفة معطيات الواقع وآلية الئية

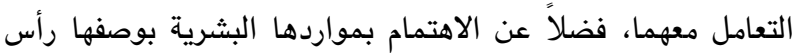

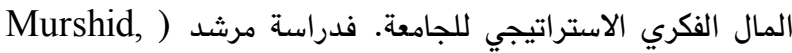

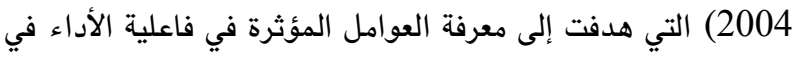

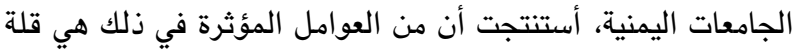

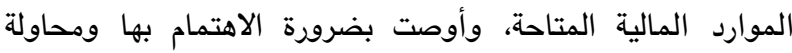

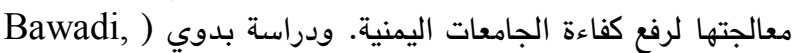

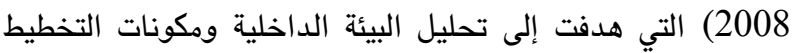
الاستراتيجي في جامعة حضرموت، وتوصلت إلى أن هناك ضعفاً في

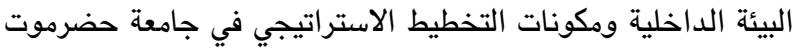

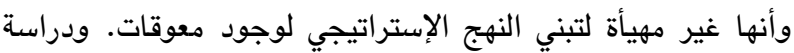
الجرادي (Aljaradi, 2011) التي هدفت إلى معرفة دور التخطيط

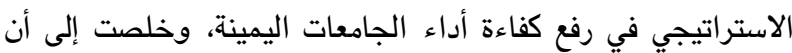

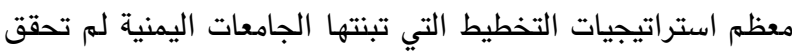

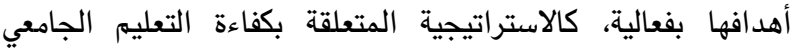
واستراتيجية البحث العلمي، واستراتيجية الاهتمام بالطالب وتطوير الائية

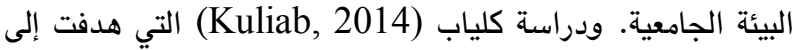
وضع تصور مقترح لتطوير الأداء الإداري لعمداء كليات التربية في

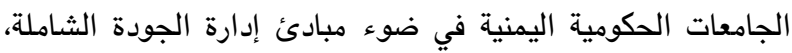

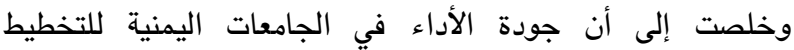
الإستراتيجي ورضا المستفيد الداخلي والخارجي كانت بدراء الإدة قليلة.

\section{مشكلة الدراسة وأسئلتها}

تتجسد مشكلة الدراسة في حقيقة ما تواجهه جامعة عدن، حيث توصل حسين (Hussein, 2001) إلى أن هناك توجهًا

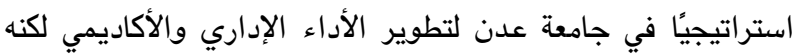

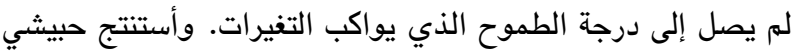
(Hubishi, 2005) الاستراتيجي في تحسين وتقوية محاور التدريس والبحث العلمي

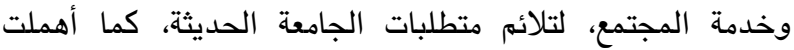
تطبيق التحليل الإستراتيجي في الكثف عن نقاط القوة ونقاط الضعف في البيئة الداخلية والفرص والتهديداتيجئ في البيئة الخارجية الإنية لإيجاد البديل الإستراتيجي، ويؤكد النخعي (Alnakhi. 2010)
وفي طليعتهم الطلبة، كون الأداء الجامعي يهتم بالطالب وما يقدم له

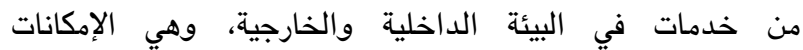
والإجراءات والطرق والأساليب وكل ما هو جزء من هيئة النظام

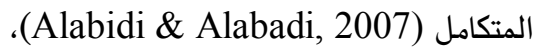

وهناك دراسات تناولت العلاقة بين التخطيط الاستراتيجي والأداء منها: دراسة جالجار (Gallagher, 2007) التي هدفت إلى معرفة العلاقة بين تعليم الطلاب والتخطيط الاستراتيجي الذي

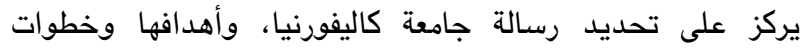
تطبيق التخطيط الاستراتيجي فيها، وأستنتجت أهمية التخطيط الاستراتيجي في تطوير أنظمة الجامعة، وتطوير مخرجات التعليم من

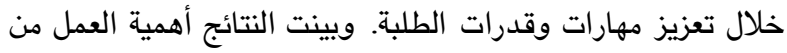
خلال ممارسة التخطيط الاستراتيجي في تحديد المهام الأكاديمية. ودراسة ديل وباريو ولوكيو (Del, Barrio \& Luque, 2009) التي هدفت إلى تقييم تصورات العملاء حول الخطة الاستراتيجية للجامعة، وذلك بتحليل احتياجات المستفيدين من خدمات الجامعة والاستفادة من تلك التصورات في عملية التخطيط الاستراتيجي. وتوصلت الدراسة إلى أن تحليل التصورات ووضعها في الاعتبار

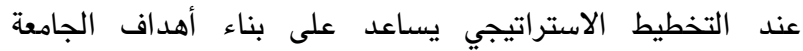
وخططها على أساس ما يحتاجه العميل منها، وأن آراء العملاء

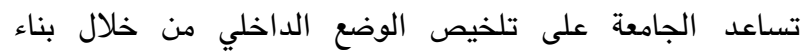
مصفوفات لمصادر القوة ونقاط الضعف الموجودة أمامها. ودراسة

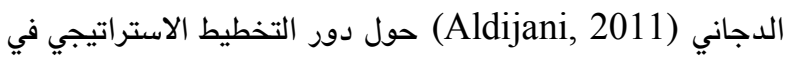

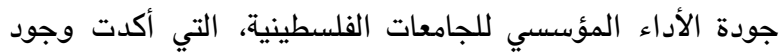

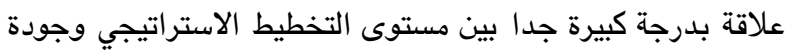

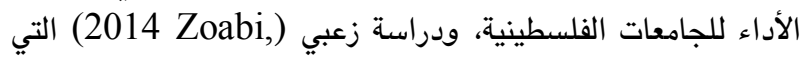
هدفت إلى معرفة اتجاهات الموظفين الإداريين نحو أثر التخطيط

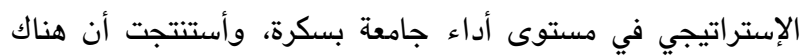

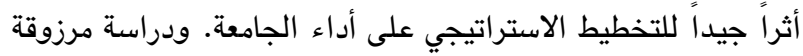
(Marzouqah, 2014)

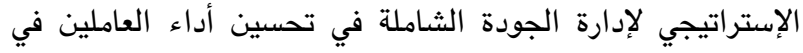

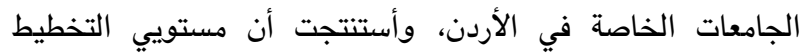

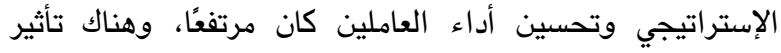
للتخطيط الإستراتيجي في تحسين أداء العاملين في تلك الجامعات. ودراسة عبد الرحمن والثويكة ( AbdulRahman \& (Alshuwaikh, 2015 التخطيط الاستراتيجي في تحسين أداء كلية فلسطين التقنية، وأستنتجت وجود دور إيجابي لتطبيق التخطيط الاستراتيجي في تحسين أداء الكلية. ودراسة الغوطي (Alghouti, 2017) التي هدفت إلى معرفة دور التخطيط الاستراتيجي في رفع الكفاءة الإنتاجية

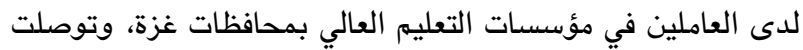

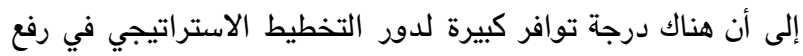

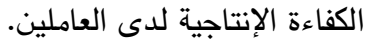


أهداف الدراسة

تهدف الدراسة الحالية إلى الكثف عن العلاقة بين مؤشرات

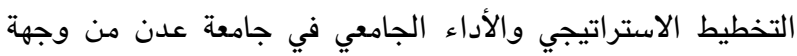
نظر طلبة وخريجي الدراسات العليا، وذلك من خلال معرفة درجة

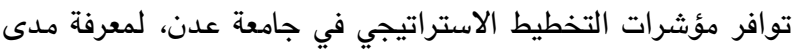

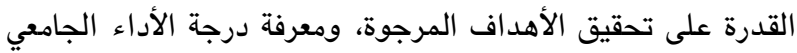

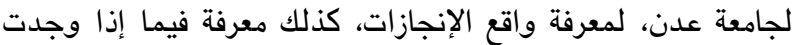

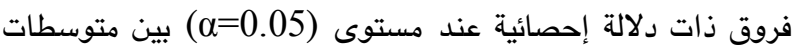

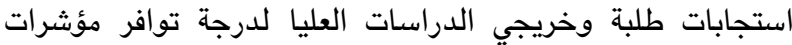

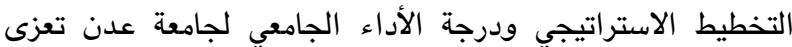

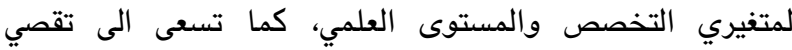
العلاقة الارتباطية بين مؤشرات التخطيط الاستراتيجي والأداء الجامعي، لمعرفة مدى العلاقة الثأثيرية بينهما.

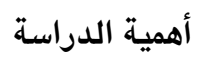

تستمد الدراسة أهميتها من أهمية التخطيط الاستراتيجي

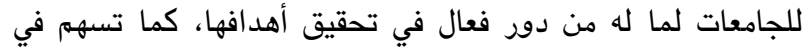

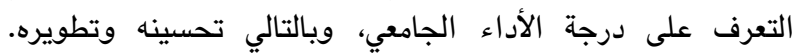

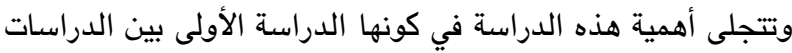

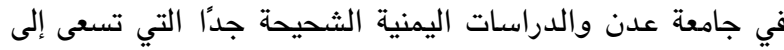

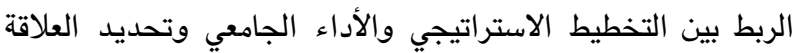

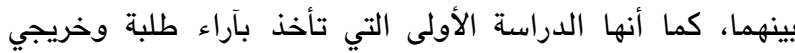

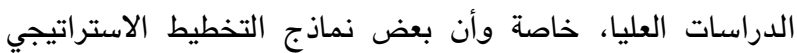

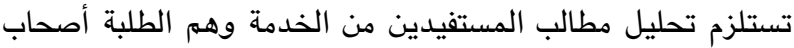

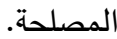

كما تبرز الأهمية من خلال الخروج بنتائج وتوصيات يستفيد

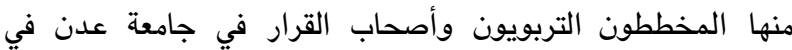

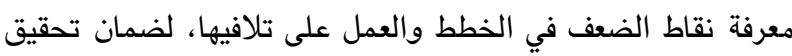

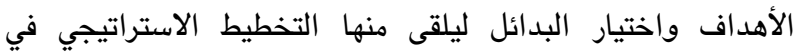

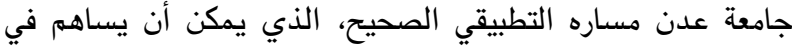

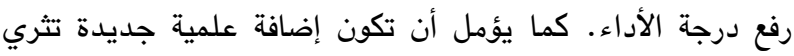
المكتبة العلمية ليستفيد منها القائمون على مؤسسات التهات التعليم العالي

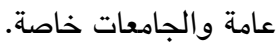

$$
\text { محددات الدراسة }
$$

اقتصرت هذه الدراسة في الحدود البشرية على طلبة وخريجي

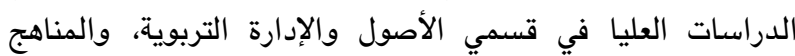
وطرق التدريس في كلية التربية بجامعة عدن للأعوام الدراسية

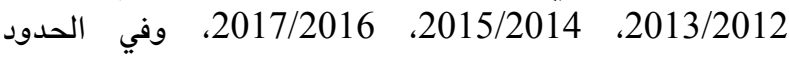

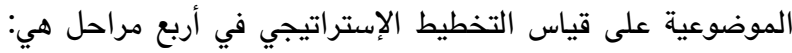
القيه، والرؤية، والرسالة، والأهداف الإستراتيجية.
ضرورة صياغة جامعة عدن لاستراتيجية معتمدة على التحليل

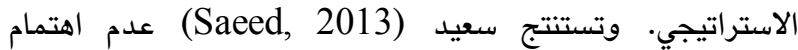

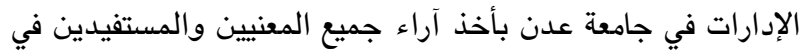

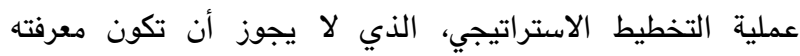

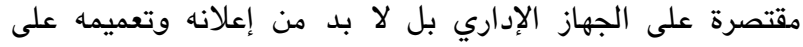

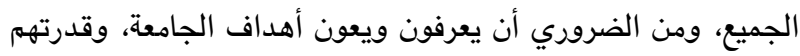

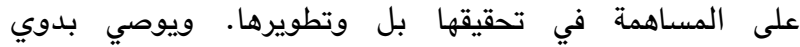
(Bawadi, 2014) الاستراتيجية لبنائها على رؤية ورسالة وأهداف واضحة تسهـم بشكل فعال في تحسين مخرجاتها، وتحديد إتجاهاتا المستقبلية. يستدل من ذلك أن جامعة عدن تعاني من صعوبات في مجال

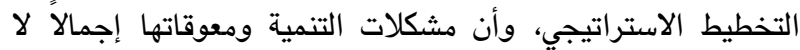

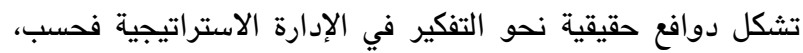

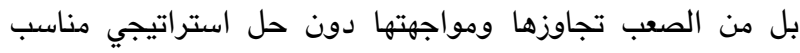

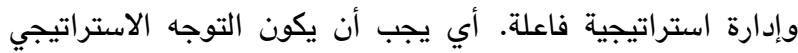

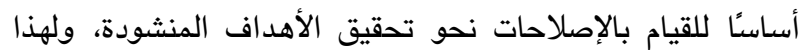
برزت الحاجة إلى الكثف عن درجة توافر مؤشرات التخطيط الاستراتيجي، وكذلك الكثف عن درجة الأداء الجامعي الذي يهتم

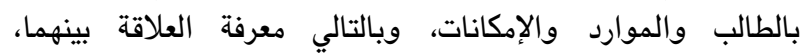
خصوصًا في ظل المتغيرات الراهنة والظروف الصعبة. ويناء عليه؛

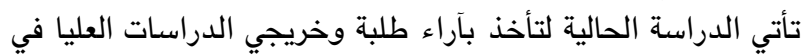

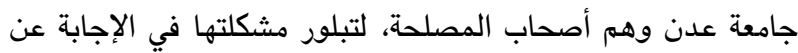

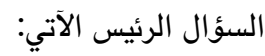

ما العلاقة بين مؤشرات التخطيط الاستراتيجي والأداء الجامعي

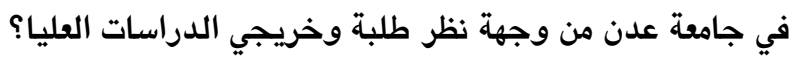
ويتفرع عن السؤال الرئيس الأسئلة الفرعية الآتية: 1. ما درجة توافر مؤشرات التخطيط الاستراتيجي في جامعة عدن

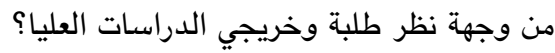
2. هل توجد فروق ذات دلالة إحصائية عند مستوى (م=0.05)

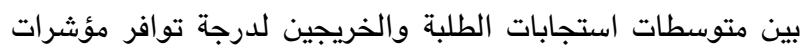
التخطيط الاستراتيجي تعزى لمتغيري التخصص والمستوى العلمي؟ لـوني 3. ما درجة الأداء الجامعي لجامعة عدن من وجهة نظر طلبة

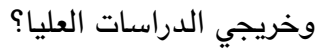

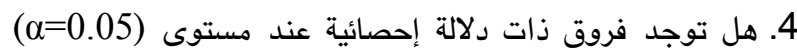

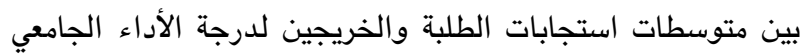

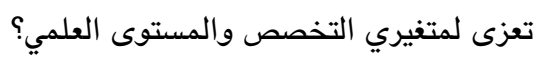
5. هل توجد علاقة ارتباطية بين مؤشرات التخطيط الاستراتيجي والأداء الجامعي؟ توجي علاقي 


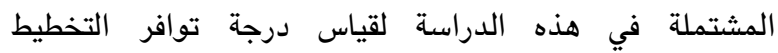

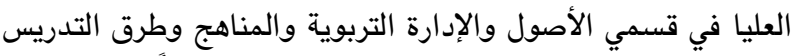
الاستراتيجي في جامعة عدن.

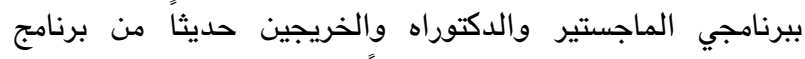

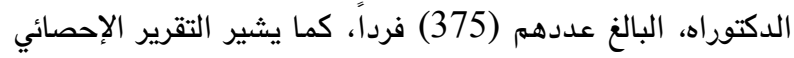
الصادر عن دائرة القبول والتسجيل في جامعة عدن للأعوام التهرئ الدراسية الإنية 2013/2012، 2015/2014، 2017/2016.

\section{عينة الدراسة}

تكونت عينة الدراسة من (144) فردًا تمثل ما نسبته

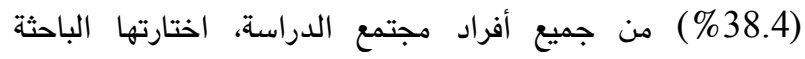

بطريقة العينة العشوائية الطبقية، كما في جدول (1) فن الدراد

جدول (1): يبين توزيع أفراد مجتمع الدراسة وعينتها وفقًا لمتفيراتها

\begin{tabular}{|c|c|c|c|c|c|c|c|}
\hline \multirow{2}{*}{ إجمالي \% } & \multirow{2}{*}{ النسبة المئوية } & \multicolumn{2}{|c|}{ عينة الدراسة } & \multicolumn{2}{|c|}{ مجتمع الدراسة } & \multirow{2}{*}{\multicolumn{2}{|c|}{ المتفيرات }} \\
\hline & & إجمالي التكرار & التكرار & إجمالي التكرار & التكرار & & \\
\hline \multirow{2}{*}{$\% 100$} & $\% 52.8$ & \multirow{2}{*}{144} & 76 & \multirow{2}{*}{375} & 198 & إدارة تربوية & \multirow{2}{*}{ التخصص } \\
\hline & $\% 47.2$ & & 68 & & 177 & مناهج وطرق تدريس & \\
\hline \multirow{3}{*}{$\% 100$} & $\% 48.6$ & & 70 & & 181 & طالب ماجستير & \multirow{3}{*}{ لمستوى العلمي } \\
\hline & $\% 34.0$ & 144 & 49 & 375 & 128 & طالب دكتوراه & \\
\hline & $\% 17.4$ & & 25 & & 66 & خريج دكتوراه حديث & \\
\hline
\end{tabular}

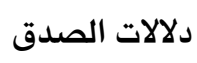

لضمان الصدق الظاهري، عرضت الباحثة الاستبانتين

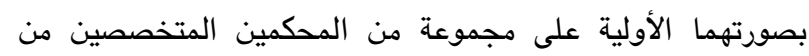

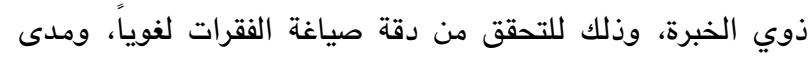

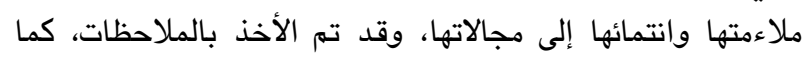

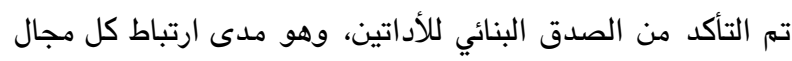

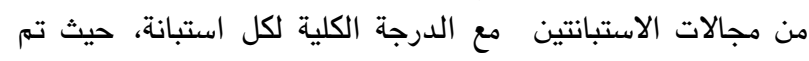

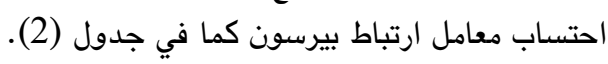

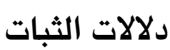
للتحقق من ثبات الاستبانتين، تم اعتماد معامل كرونباخ الفا ،

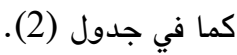

أعدت الباحثة استبانتين لقياس العلاقة بين مؤشرات التخطيط

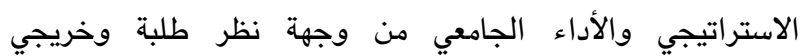

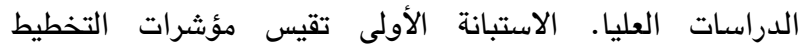

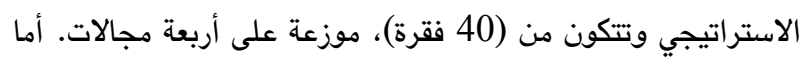

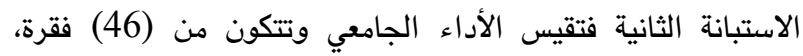

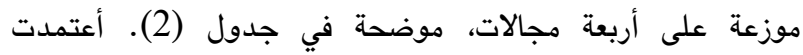

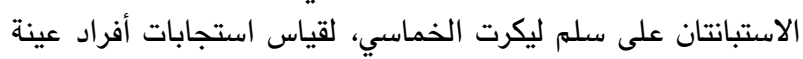

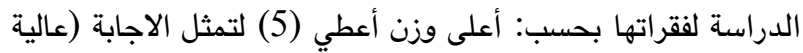

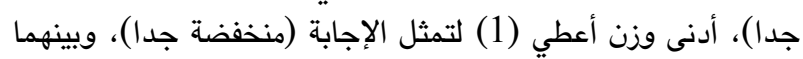

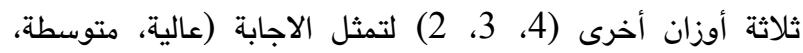
منخفضة) على التوالي. 
جدول (2): قيمم معاملات ارتباط بيرسون ومعاملات كرونباخ الفا لكل من أداتي الدراسة ومجالاتها

\begin{tabular}{|c|c|c|c|c|c|c|c|c|c|}
\hline كرونباخ & لبيرسون للإرتباط & الفقرات & مجالات الأداة الثانية & & كرونباخ & لمعامل بيرسون & الفقرات & مجالات الأداة الأولى & \\
\hline .94 & .850 & 15 & العملية التعليمية & 1 & .88 & .824 & 8 & القيم & 1 \\
\hline .91 & .923 & 9 & البحث العلمي & 2 & .90 & .918 & 9 & 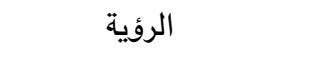 & 2 \\
\hline .87 & .888 & 13 & الخدمات في البيئة الداخلية & 3 & .92 & .917 & 9 & 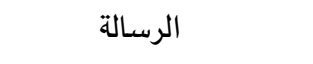 & 3 \\
\hline .86 & .863 & 9 & الخدمات في البيئة & 4 & .92 & .888 & 14 & الأهداف الإستراتيجية & 4 \\
\hline .97 & - & 46 & الكلي للأداء الجامعي & & .97 & - & 40 & الكلي لمؤشرات التخطيط & \\
\hline
\end{tabular}

$$
\text { النتائج }
$$

المعالجة الإحصائية ومعيار التصنيف

نتائج السؤال الأول: ما درجة توافر مؤشرات التخطيط الاستراتيجي في جامعة عدن الأول: ما لن وجهة نظر طلبة وخريجي الدراسات العليا؟

للاجابة عن هذا السؤال، تم حساب المتوسطات الحسابية

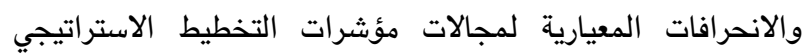
والأداة ككل بحسب جدول (3).
تم حساب المتوسطات الحسابية والانحرافات المعيارية، كما

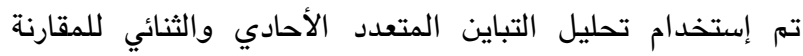

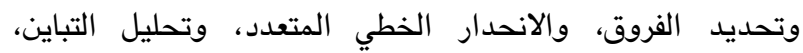

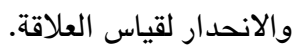

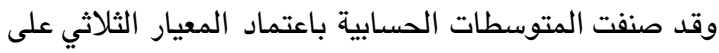

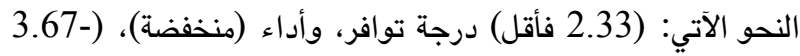

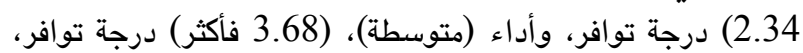

وأداء (عالية).

جدول (3): المتوسطات الحسابية والانحرافات المعيارية، ودرجة التوافر لفقرات كل مجال والأداة ككل لمؤشرات التخطيط الإستراتيجي

\begin{tabular}{|c|c|c|c|c|c|}
\hline التوافر & $\begin{array}{l}\text { الانحراف } \\
\text { المعياري }\end{array}$ & الحسابي & 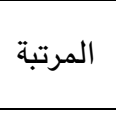 & 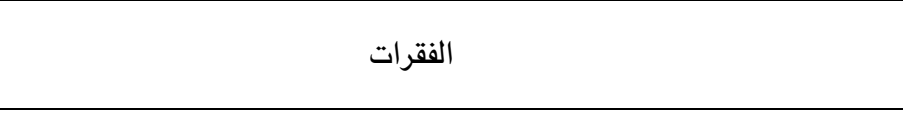 & p \\
\hline متوسطة & 1.04 & 3.58 & 1 & تحرص على السمعة الجيدة بوصفها مركز إشعاع علمي وحضاري & 1 \\
\hline 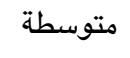 & 0.96 & 2.78 & 7 & تراعي الشفافية والديمقراطية في جميع معاملاتها الداخلية والخارجية & 2 \\
\hline 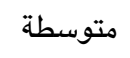 & 1.12 & 3.50 & 2 & توافق القيم الجامعية مع القيم الإسلامية & 3 \\
\hline 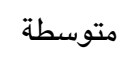 & 1.00 & 3.01 & 6 & تعزز الشعور بالمسئولية والولاء للجامعة والمواطنة الصالحة & 4 \\
\hline 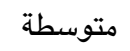 & 1.02 & 3.17 & 4 & تدعم حقوق الملكية الفكرية والحرية الأكاديمية بحسب السياسات والقوانين & 5 \\
\hline 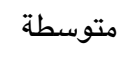 & 1.07 & 3.04 & 5 & توفر ميثاق أخلاق المهنة (للأطباء، المعلمين، المحامين،... وغيرهم) & 6 \\
\hline 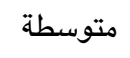 & 0.93 & 3.23 & 3 & تعكس الأبعاد الأخلاقية في المقررات الدراسية وجميع نظم التقويم & 7 \\
\hline 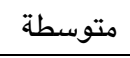 & 1.03 & 3.17 & 4 & تنمي الاتجاهات الإيجابية نحو العلم والتعلم الذاتي والمستمر مدى الحياة & 8 \\
\hline 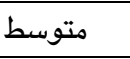 & 0.75 & 3.19 & 1 & مجال القيم & \\
\hline متوسطة & 1.03 & 3.01 & 2 & موضحة لجميع المستفيدين داخليا وخارجيا & 1 \\
\hline 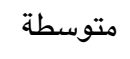 & 1.08 & 2.82 & 6 & منشورة للمجتمع، وأعضاء هيئة التدريس، والإداريين، والطلاب & 2 \\
\hline 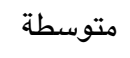 & 0.98 & 2.87 & 4 & تبرز في الأنشطة التعليمية والبحوث العلمية والخدمات المجتمعية & 3 \\
\hline 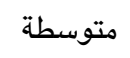 & 1.04 & 3.06 & 1 & تطمح للريادة في تقديم الخدمات في المجالات العلمية النظرية والتطبيقية & 4 \\
\hline 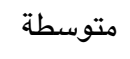 & 0.98 & 2.94 & 3 & تسعى لكسب ثقة المستفيدين من خدماتها (طلبة، أرباب العمل،....) & 5 \\
\hline 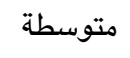 & 0.97 & 2.87 & 4 & تتطلع إلى تعزيز دورها بإنجازات بحثية متميزة محليا، إقليميا، عالميا & 6 \\
\hline 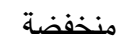 & 0.90 & 2.59 & 8 & تسعى إلى استثمار تكنولوجيا المعلومات والاتصال وبشكل مناسب & 7 \\
\hline 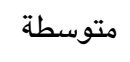 & 1.09 & 2.74 & 7 & تطمح للريادة في إعداد الكفاءات العلمية المبدعة والمبتكرة ذات الجودة & 8 \\
\hline 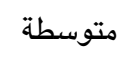 & 1.16 & 2.83 & 5 & تطمح لتحقيق الاعتماد الأكاديمي والعالمية & 9 \\
\hline
\end{tabular}




\begin{tabular}{|c|c|c|c|c|c|}
\hline متوسطة & 0.77 & 2.86 & 2 & 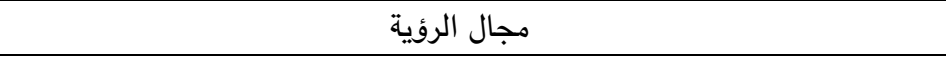 & \\
\hline متوسطة & 0.93 & 3.22 & 1 & تعكس صورة واضحة داخليا وخارجيا عن الغرض الذي وجدت من أجله & 1 \\
\hline 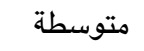 & 1.05 & 2.94 & 2 & منشورة للمجتمع، وأعضاء هيئة التدريس، والإداريين، والطلاب & 2 \\
\hline 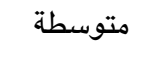 & 0.89 & 2.93 & 3 & تترجم إلى أهداف استراتيجية محددة وواضحة & 3 \\
\hline 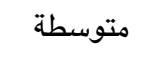 & 0.95 & 2.79 & 4 & تحقق وظائف الجامعة (التدريس، البحث العلمي، خدمة المجتمع) بجودة عالية & 4 \\
\hline 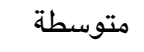 & 0.93 & 2.72 & 5 & تقدم خدمة تعليمية ذات جودة متميزة & 5 \\
\hline 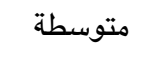 & 0.95 & 2.42 & 8 & تواكب التطورات التكنولوجية الحديثة في أساليب وتقنيات التعليم والتعلم & 6 \\
\hline 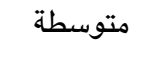 & 0.93 & 2.51 & 7 & تواكب التطور في أساليب الإدارة الحديثة & 7 \\
\hline 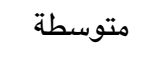 & 0.96 & 2.68 & 6 & تستقطب أعضاء هيئة تدريس أكفاء وفاعلين & 8 \\
\hline 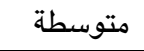 & 0.95 & 2.51 & 7 & تتبنى الطلاب المتفوقين & 9 \\
\hline 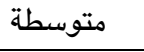 & 0.73 & 2.75 & 3 & 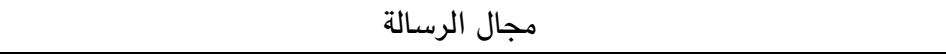 & \\
\hline متوسطة & 0.91 & 3.12 & 2 & موضوعاه في ضوء رسالة واضحة لديها & 1 \\
\hline 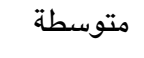 & 0.90 & 2.97 & 3 & شاملة وواضحة وقابلة للقياس مع الغرض الذي أنثأت لتحقيقه & 2 \\
\hline 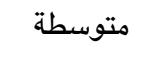 & 0.97 & 2.71 & 6 & منشورة علنا للمجتمع، وأعضاء هيئة التدريس، والإداريين، والطلاب & 3 \\
\hline 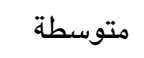 & 0.89 & 2.76 & 5 & تتيح فرص الدراسة المتخصصة والمتعمقة في ميادين المعرفة المختلفة & 4 \\
\hline 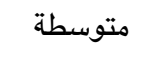 & 0.83 & 2.65 & 8 & تسخر المعارف والمهارات العلمية والتطبيقية لحل المشكلات بفاعلية & 5 \\
\hline 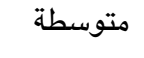 & 0.88 & 2.97 & 3 & ترسخ الرؤية الصحيحة والتراث التاريخي والثقافي والحضاري للإسلام & 6 \\
\hline 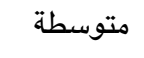 & 0.86 & 2.60 & 9 & تهتم بالمهارات العلمية النظرية والتطييقية والإبداعية والابتكارية & 7 \\
\hline 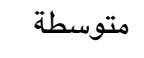 & 1.10 & 3.13 & 1 & تعنى باللغة العربية وتدريسها وتعميم استعمالها في مختلف المجالات & 8 \\
\hline 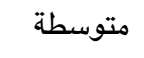 & 0.88 & 2.80 & 4 & تقترح المعالجات العلمية لقضايا التنمية الاجتماعية والاقتصادية والثقافية & 9 \\
\hline 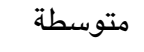 & 0.95 & 2.70 & 7 & توثق الروابط العلمية والثقافية مع الجامعات والمراكز العربية والأجنبية & 10 \\
\hline 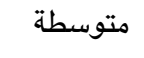 & 0.94 & 2.47 & 12 & تسهم ببرامج تأهيل وتدريب أثناء الخدمة لرفع كفاءة العاملين في العمل & 11 \\
\hline 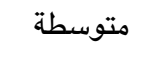 & 0.87 & 2.44 & 13 & تهتم بالتكنولوجيا الحديثة للاستفادة منها في تطوير المجتمع & 12 \\
\hline 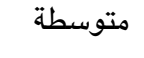 & 0.97 & 2.51 & 11 & تستحدث تخصصات جديدة ومتطورة وفقا لاحتياجات المجتمع وسوق العمل & 13 \\
\hline 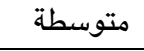 & 0.88 & 2.54 & 10 & تلبي احتياجات المجتمع من الفنيين والخبراء لخدمة التنمية الشاملة & 14 \\
\hline 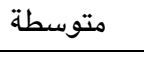 & 0.64 & 2.74 & 4 & مجال الأهداف & \\
\hline متوسطة & 0.64 & 2.88 & & الأداة ككل & \\
\hline
\end{tabular}

فقرة (8) في المرتبة الأولى بدرجة توافر (متوسطة)، بأعلى متوسط

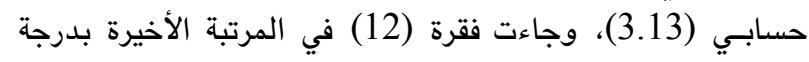
توافر (متوسطة)، بأدنى متوسط حسابـي (2.44)، فئرة (12.13). وعلى مستوى الأداة ككل، جاءت متوافرة بدرجة توافر

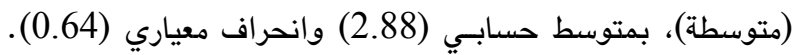

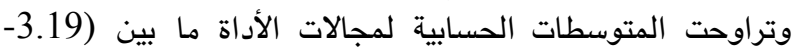

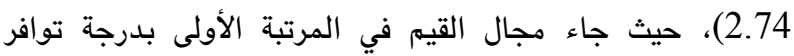

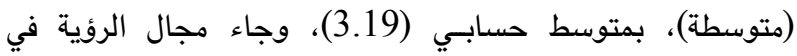

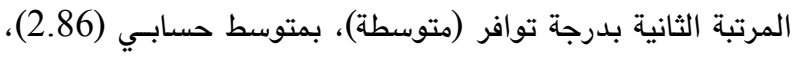

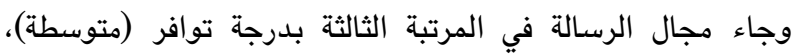

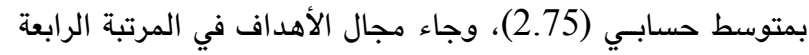

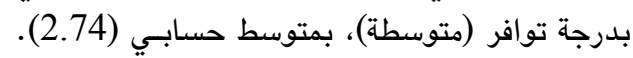

بالإشارة للنتائج الموضحة في الجدول (3) تبين أن

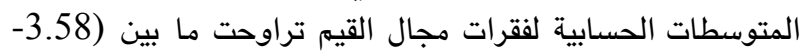

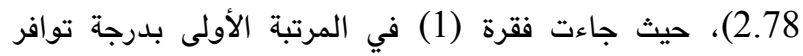

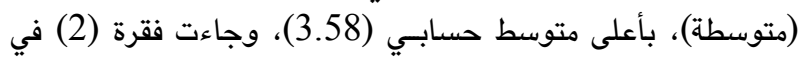

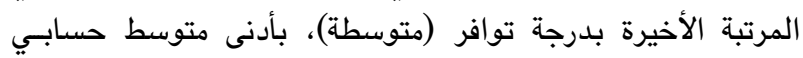

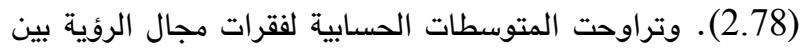

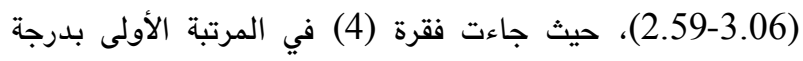

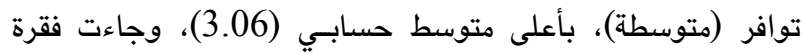

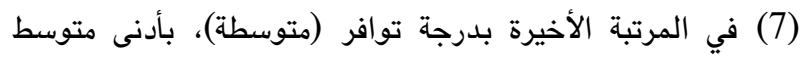

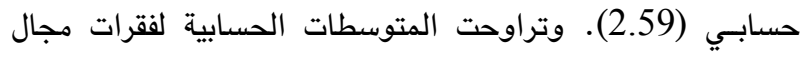

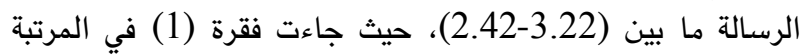

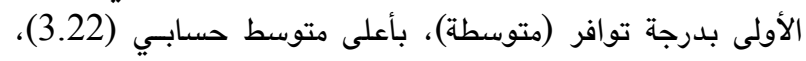

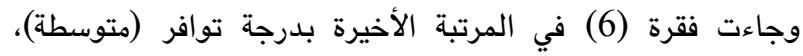

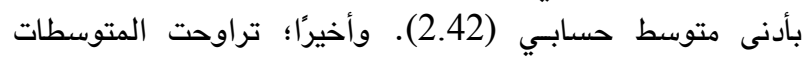

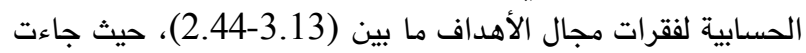


للاجابة عن هذا السؤال، تم استخدام اختبارات تحليل

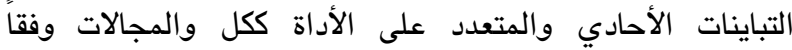

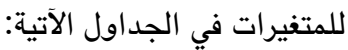

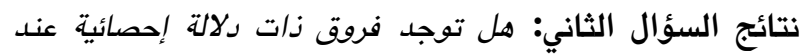
مستوى (1)=0.05) بين متوسطات استجابات الطلبة والخريجين

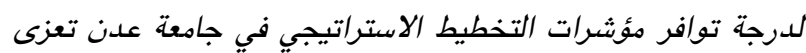

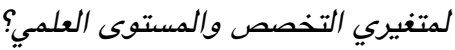

جدول (4): المتوسطات الحسابية والإنحرافات المعيارية للأداة ككل والمجالات بحسب المتغيرات

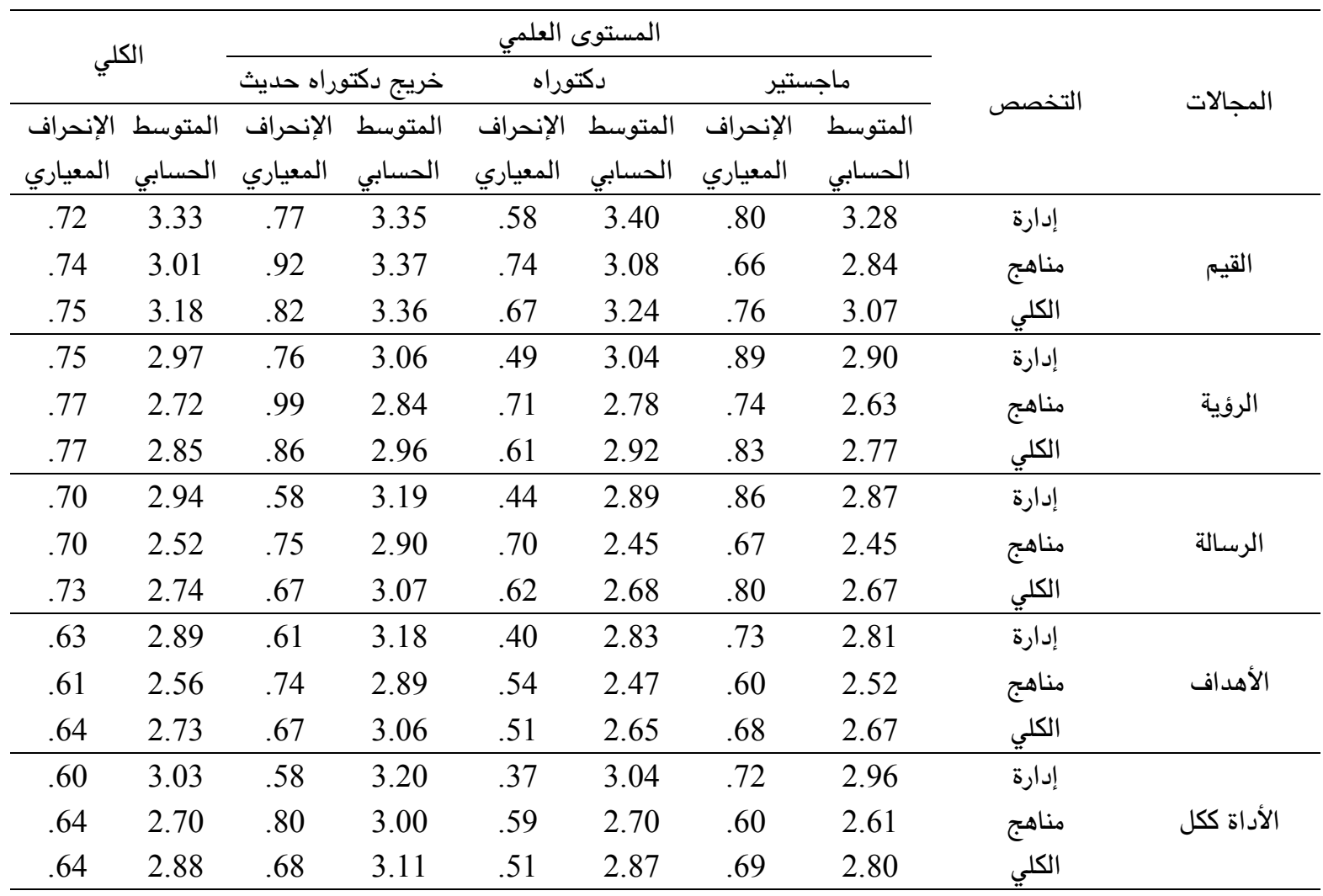

للفروق، تم استخدام تحليل التباين الأحادي والمتعدد على الأداة

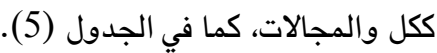

بالإشارة للنتائج الموضحة في الجدول (4) هناك تباين ظاهري

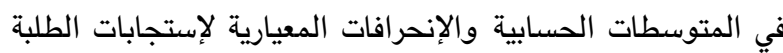

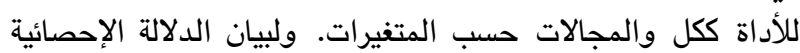

جدول (5): تحليل التباين الأحادي والمتعدد للأداة ككل والمجالات حسب متفيرات التخصص والمستوى العلمي والتفاعل بينها

\begin{tabular}{|c|c|c|c|c|c|c|}
\hline مستوى الدلالة & قيمة (ف) & متوسط المربعات & درجة الحرية & مجموع المربعات & مصدر التباين & المجالات \\
\hline .073 & 3.268 & 1.763 & 1 & 1.763 & \multirow{4}{*}{$\begin{array}{c}\text { الدلالة الإحصائية }=084 \text { التخصص } 0.084 \\
0.026\end{array}$} & القيم \\
\hline .081 & 3.086 & 1.824 & 1 & 1.824 & & الرؤية \\
\hline .003 & 8.902 & 4.389 & 1 & 4.389 & & الرسالة \\
\hline .006 & 7.697 & 2.934 & 1 & 2.934 & & الأهداف \\
\hline .167 & 1.816 & .980 & 2 & 1.960 & \multirow{4}{*}{ 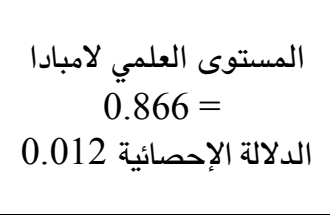 } & القيم \\
\hline .444 & .816 & .482 & 2 & .964 & & الرؤية \\
\hline .050 & 3.069 & 1.513 & 2 & 3.026 & & الرسالة \\
\hline .024 & 3.843 & 1.465 & 2 & 2.930 & & الأهداف \\
\hline .423 & .866 & .468 & 2 & .935 & \multirow{4}{*}{ التخصص* الامبادا = المستوى العلمي 0.975 الإلحصائية 0.902} & القيم \\
\hline .990 & .010 & .006 & 2 & .012 & & الرؤية \\
\hline .903 & .102 & .050 & 2 & .101 & & الرسالة \\
\hline .945 & .056 & .022 & 2 & .043 & & الأهداف \\
\hline
\end{tabular}


حمزة

\begin{tabular}{|c|c|c|c|c|c|c|}
\hline مستوى الدلالة & قيمة (ف) & متوسط المربعات & درجة الحرية & مجموع المربعات & مصدر التباين & المجالات \\
\hline & & .540 & 138 & 74.461 & \multirow{4}{*}{ الخطأ } & القيم \\
\hline & & .591 & 138 & 81.581 & & الرؤية \\
\hline & & .493 & 138 & 68.037 & & الرسالة الرسال \\
\hline & & .381 & 138 & 52.601 & & الأهداف \\
\hline & & & 144 & 1542.219 & \multirow{4}{*}{ المجموع } & القيم \\
\hline & & & 144 & 1261.765 & & الرؤية \\
\hline & & & 144 & 1163.173 & & 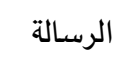 \\
\hline & & & 144 & 1138.898 & & الأهداف \\
\hline .010 & 6.788 & 2.630 & 1 & 2.630 & التخصص & \\
\hline .105 & 2.288 & .886 & 2 & 1.773 & المستوى العلمي & \\
\hline \multirow[t]{3}{*}{.855} & .157 & .061 & 2 & 0.122 & التخصص*المستوى آلعلمي & الأداة ككل \\
\hline & & .387 & 138 & 53.455 & 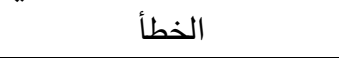 & \\
\hline & & & 144 & 1255.330 & المجموع & \\
\hline
\end{tabular}

على مجالي القيه، والرؤية، والأداة ككل. وجود فروق ذات دلالة

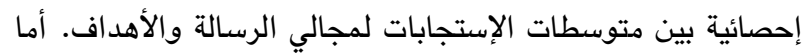

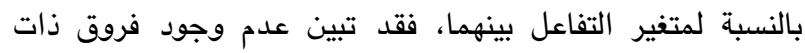
دلالة إحصائية (1) $(\alpha=05)$ على الأداة ككل ومجالاتها. ولتحديد مواقع الفروق بين فئات العينة، تم استخدام اختبار

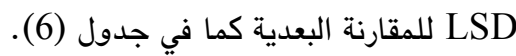

بالإشارة للنتائج الموضحة في الجدول (5)، لمتغير التخصص،

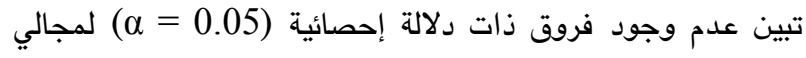
القيم والرؤية. ووجود فروق فروق ذات دلات دلالة إحصائية بين متوسطي

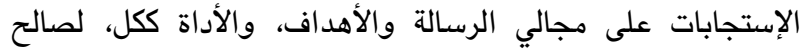

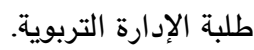
وبالنسبة لمتغير المستوى العلمي، تبين عدم وجود فروق إلئي ذات دلالة إحصائية عند ( $\left.{ }^{2}=0.05\right)$ بين متوسطات الإستجابات

جدول (6): نتائج اختبار LSD للمقارنة البعدية اتحديد إتجاهات الفروق

\begin{tabular}{|c|c|c|c|c|}
\hline مستوى & فارق المتوسطات & \multicolumn{2}{|c|}{ المستوى العلمي } & \multirow{2}{*}{ المجالات } \\
\hline الدلالة & $\mathrm{J}-\mathrm{I}$ & $\mathrm{J}$ & I & \\
\hline 0.017 & $.394^{*}$ & ماجستير & \multirow{4}{*}{ خريج دكتوراه حديث } & \multirow{2}{*}{ الرسالة } \\
\hline 0.025 & $.390^{*}$ & دكتوراه & & \\
\hline 0.009 & $.380^{*}$ & ماجستير & & \multirow{2}{*}{ الأهداف الإستراتيجبة } \\
\hline 0.009 & $.402^{*}$ & دكتوراه & & \\
\hline
\end{tabular}

نتائج السؤال الثالث: ما درجة الأداء الجامعي لجامعة عدن من لنوراه وجهة نظر طلبة وخريجي الدراسات العليا؟ الثاء لأل العاء

للاجابة عن هذا السؤال، تم حساب المتوسطات الحسابية

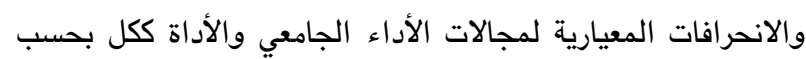

بالإشارة للنتائج الموضحة في الجدول (6)، تيين أن مواقع

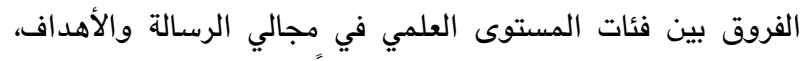
جاءت جميعها لصالح خريج دكتوراه حديثًا.

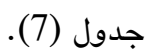


جدول (7): المتوسطات الحسابية والانحرافات المعيارية، ودرجة الأداء لفقرات كل مجال والأداة ككل للأداء الجامعي

\begin{tabular}{|c|c|c|c|c|c|}
\hline 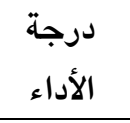 & المعياري - الانحراف & المتوسط الحسابي & 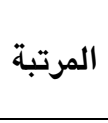 & 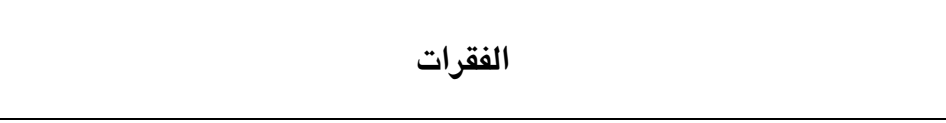 & م \\
\hline 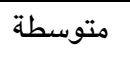 & 1.12 & 3.63 & 1 & تتوفر المعلومات الصحيحة للبرامج والرسوم الدراسية & 1 \\
\hline 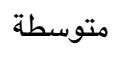 & 1.15 & 3.20 & 3 & توجد قواعد بيانات للتعامل مع السجلات الأكاديمية للطلاب & 2 \\
\hline متوسطة & 0.99 & 3.03 & 5 & تحفظ حقوق الطلاب بتطبيق اللوائح والأنظمة للدراسات العليا بعدالة & 3 \\
\hline 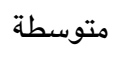 & 1.04 & 2.82 & 7 & توحد برامج تعليم عالي متنوعة مواكبة للتطورات العلمية والعملية الحديثة & 4 \\
\hline 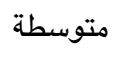 & 1.02 & 2.72 & 8 & ترتبط المقررات الدراسية بالتطبيق والممارسة العلمية & 5 \\
\hline 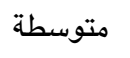 & 0.97 & 3.26 & 2 & توجد الهيئة التدريسية المؤهلة بكفاءة للبرامج العلمية & 6 \\
\hline 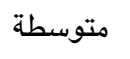 & 0.95 & 2.50 & 13 & تتوفر الإمكانات والموارد المتطورة (أجهزة، قاعات دراسية، مختبرات،...) & 7 \\
\hline 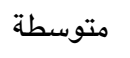 & 0.95 & 2.51 & 12 & توجد مصادر تعليم وتعلم حديثة ومختلفة يسهل الوصول إليها & 8 \\
\hline 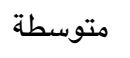 & 1.05 & 2.72 & 8 & توجد في المكتبة (مراجع، مصادر، قواعد بيانات إلكترونيه، انترنت،...) & 9 \\
\hline 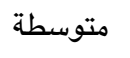 & 0.98 & 3.05 & 4 & تتابع الأقسام العلمية العمليات التعليمية (خطط دراسية، طرق تدريس،...) & 10 \\
\hline 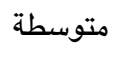 & 1.01 & 2.72 & 8 & تتوفر آلية تقييم موضوعي لأداء أعضاء الهيئة التدريسية & 11 \\
\hline 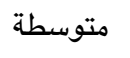 & 0.99 & 2.90 & 6 & تراعى الفروق الفردية بين الطلاب & 12 \\
\hline 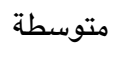 & 0.95 & 2.65 & 9 & تراعى تزايد نسبة أعداد الطلاب بالنسبة للمدرسين & 13 \\
\hline 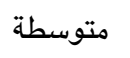 & 0.94 & 2.59 & 10 & تتوفر الأجواء الأكاديمية المشجعة لتميز في الأداء للعمليات التعليمية & 14 \\
\hline 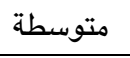 & 1.05 & 2.56 & 11 & تشرك ممثلين عن مواقع العمل لمراجعة المقررات الدراسية لتطويرها & 15 \\
\hline 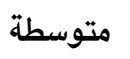 & 0.75 & 2.86 & 1 & مجال العملية التعليمية العية & \\
\hline متوسطة & 1.06 & 2.90 & 3 & تهتم بتحقيق أهداف البحث العلمي & 1 \\
\hline 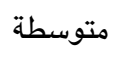 & 1.00 & 2.42 & 6 & تؤمن مقومات البحث العلمي من تمويل، ومختبرات، ومصادر،....) & 2 \\
\hline 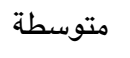 & 1.06 & 3.35 & 1 & تهتم بمستوى الأشراف والمناقشة على رسائل الماجستير والدكتوراه & 3 \\
\hline 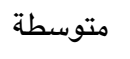 & 1.01 & 2.78 & 5 & تدعم البحوث العلمية وطرق إجراءاتها وتقويمها وإثرائها للمعرفة & 4 \\
\hline 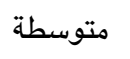 & 1.07 & 2.87 & 4 & توفر النشرات الدورية للرسائل العلمية المجازة شاملة الملخص والنتائج & 5 \\
\hline 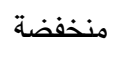 & 1.04 & 2.32 & 7 & تهتم بتوظيف نتائج البحوث العلمية للدراسات العليا & 6 \\
\hline 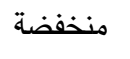 & 0.93 & 2.10 & 9 & تشجع الطلاب بجوائز ومكافآت عند التفقق الدراسي والبحثي المتميزة & 7 \\
\hline 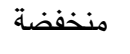 & 0.96 & 2.25 & 8 & توفر فرص المشاركة للباحثين في الأنثطة العلمية داخليا وخارجيا & 8 \\
\hline 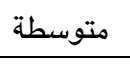 & 1.02 & 3.04 & 2 & تشجع حرية الفكر والتأليف والترجمة والنشر في مختلف المجالات & 9 \\
\hline 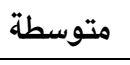 & 0.78 & 2.67 & 2 & 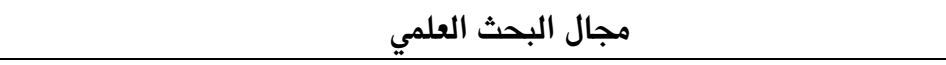 & \\
\hline 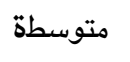 & 1.0 & 3 & 2 & توجد معايير واضحة ومعلنة للقبول والتسجيل تطبق على الجميع & 1 \\
\hline 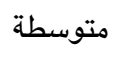 & 0.93 & 2.60 & 6 & تتصف سياسات القبول والتسجيل بالثفافية والدقة & 2 \\
\hline 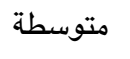 & 1.15 & 3.63 & 1 & يوجد دليل للطالب يتضمن كل ما يلزم من معلومات & 3 \\
\hline 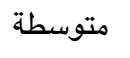 & 1.11 & 3.03 & 3 & يوجد نظام للإعلام بالأنظمة والتعليمات التي تخص الطلاب & 4 \\
\hline 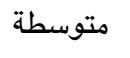 & 0.92 & 2.71 & 5 & تقوم الإدارات المتخصصة بمهامها في خدمة الطلاب بسهولة ويسر & 5 \\
\hline 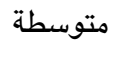 & 0.92 & 2.49 & 8 & تهتم بمشكلات الطلاب والعمل على حلها & 6 \\
\hline 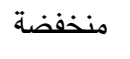 & 0.85 & 1.98 & 11 & توجد الأنثطة اللامنهجية لملئ وقت الفراغ والراحة النفسية للطلاب & 7 \\
\hline 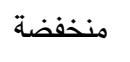 & 0.85 & 1.99 & 10 & تعمل بآليات معلنة لتلقي الثكاوى والمقترحات والاستجابة لها & 8 \\
\hline 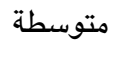 & 1.20 & 2.75 & 4 & توجد الخدمات الطلابية (التصوير، المواد القرطاسية والمكتبية، المطاعمه....) & 9 \\
\hline 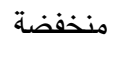 & 0.82 & 1.97 & 12 & توفر نظاما وإجراءات محددة تكفل تكافؤ الفرص في التعيين والتأهيل & 10 \\
\hline 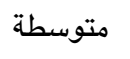 & 0.82 & 2.38 & 9 & توفر البيئة الجامعية الملبية لاحتياجات وتوقعات الطلاب & 11 \\
\hline 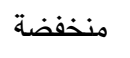 & 0.77 & 1.67 & 13 & تشرك الطلاب في صياغة رؤية ورسالة وأهداف الجامعة & 12 \\
\hline 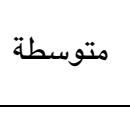 & 0.78 & 2.59 & 7 & التنظيه، العوامل المؤثرة الداخلية (الموارد البشرية، الخدمات الإدارية، & 13 \\
\hline
\end{tabular}




\begin{tabular}{|c|c|c|c|c|c|}
\hline الأداء & 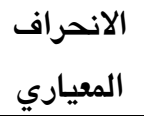 & المتوسط & 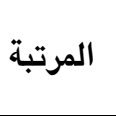 & 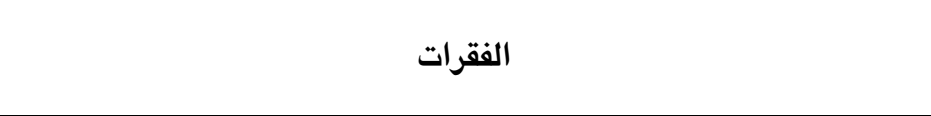 & p \\
\hline 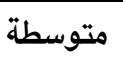 & 0.59 & 2.53 & 3 & مجال خدمات البيئة الداخلية & \\
\hline متوسطة & 0.88 & 2.37 & 6 & توجه الطلاب لخدمة المجتمع المحلي & 1 \\
\hline متوسطة & 1.07 & 2.75 & 2 & تطلع لتأهل الخريجين بشتى التخصصات التي تلبي احتياجات سوق العمل & 2 \\
\hline 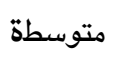 & 1.00 & 2.76 & 1 & تطلع لتخلق شراكة مع مؤسسات وأفراد المجتمع المحلي & 3 \\
\hline 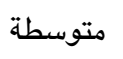 & 0.98 & 2.56 & 4 & ترفد المجتمع المحلي بخريجين على مستوى عالٍٍ من الكفاءة & 4 \\
\hline 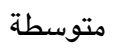 & 0.88 & 2.69 & 3 & تنمي المواقف والمهارات الإيجابية نحو العمل بشكل عام & 5 \\
\hline 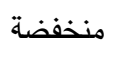 & 0.85 & 1.69 & 8 & تهتم بمتابعة معدلات فرص العمل وتوظيف الطلاب الخريجين & 6 \\
\hline منخفضة & 0.86 & 2.27 & 7 & تاعلة العوامل الاقتصادية (دعم الدولة، السوق، مستوى دخل الفرد، & 7 \\
\hline 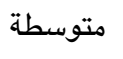 & 0.87 & 2.56 & 4 & تراعي العوامل السياسية (الإستقرارالسياسي، سياسة الحكومة نحو التعليم،،.) & 8 \\
\hline 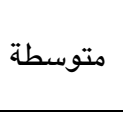 & 090 & 2.51 & 5 & تراعي العوامل الاجتماعية (الحاجة للدراسات العليا، المسئولية الاجتماعية، & 9 \\
\hline 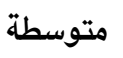 & 0.64 & 2.46 & 4 & مجال خدمات البيئة الخارجية & \\
\hline متوسطة & 0.61 & 2.63 & & الأداة ككل & \\
\hline
\end{tabular}

وبالنسبة الى متوسط الأداة ككل، فقد جاء بدرجة أداء (متوسطة)، ومتوسط حسابس (2.63) وانحراف معياري (0.61).

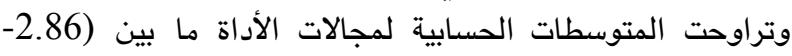

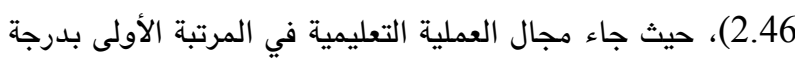

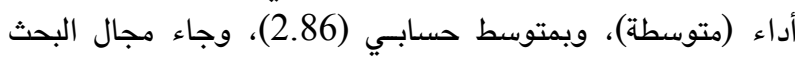

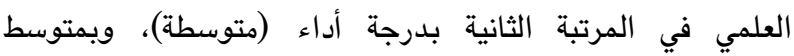

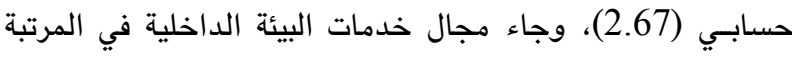

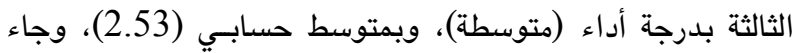

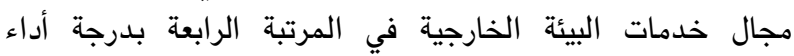
(متوسطة)، وبمتوسط حسابسي (2.46).

نتائج السؤال الرابع: هل توجد فروق ذات دلالة إحصائية عند

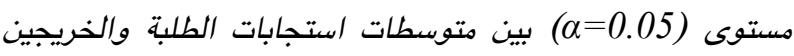

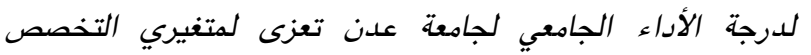

$$
\text { والمستوى العلمي؟ لأداء الجمي }
$$

للاجابة عن هذا السؤال، تم إجراء تحليل التباينات الأحادي

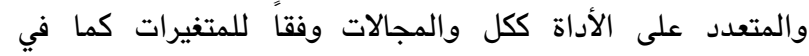

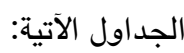

بالإشارة للنتائج الموضحة في الجدول (7)، تبين أن

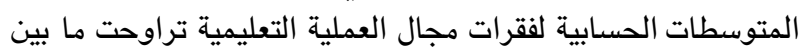

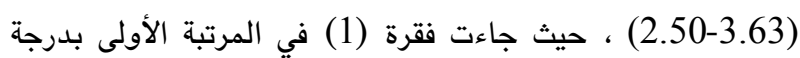

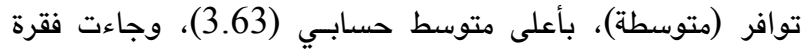

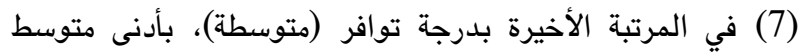

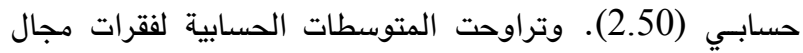

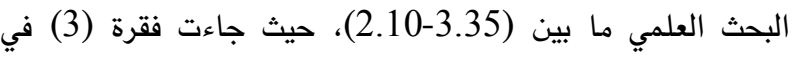

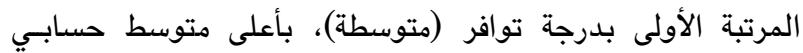

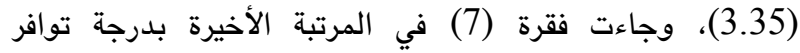

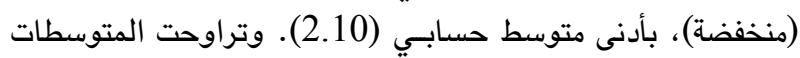
الحسابية لفقرات مجال خدمات البيئة الداخلية ما بين (3.63-

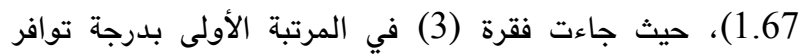

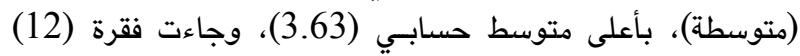

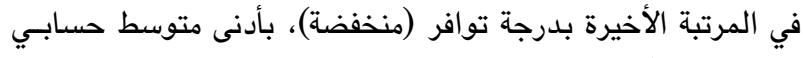

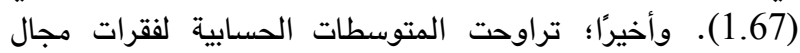

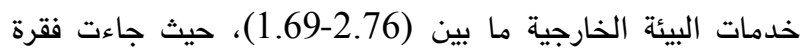

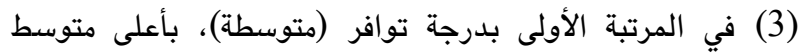

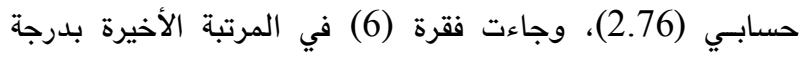
توافر (منخفضة)، بأدنى متوسط حسابي (1.69). 
جدول (8): المتوسطات الحسابية والإنحرافات المعيارية لمتوسطات الإستجابات للأداة ككل والمجالات بحسب المتغيرات

\begin{tabular}{|c|c|c|c|c|c|c|c|c|c|}
\hline \multirow{2}{*}{\multicolumn{2}{|c|}{ الكلي }} & \multicolumn{6}{|c|}{ المستوى العلمي } & \multirow{4}{*}{ التخصص } & \multirow{4}{*}{ المجالات } \\
\hline & & \multicolumn{2}{|c|}{ خريج دكتوراه حديث } & \multicolumn{2}{|c|}{ دكتوراه } & \multicolumn{2}{|c|}{ ماجستير } & & \\
\hline الإنحراف & المتوسط & الإنحراف & المتوسط & الإنحراف & المتوسط & الإنحراف & المتوسط & & \\
\hline المعياري & الحسابي & المعياري & الحسابي & المعياري & الحسابي & المعياري & الحسابي & & \\
\hline .74 & 3.01 & .56 & 3.81 & .43 & 3.09 & .74 & 2.66 & إدارة & \\
\hline .71 & 2.67 & .76 & 3.21 & .60 & 2.46 & .70 & 2.64 & مناهج & الماليمليه \\
\hline .75 & 2.85 & .71 & 3.55 & .60 & 2.78 & .72 & 2.65 & الكلي & \\
\hline .73 & 2.86 & .46 & 3.54 & .52 & 2.62 & .79 & 2.76 & إدارة & \\
\hline .78 & 2.45 & 1.08 & 2.88 & .64 & 2.29 & .72 & 2.42 & مناهج & البول \\
\hline .78 & 2.66 & .84 & 3.25 & .60 & 2.46 & .77 & 2.60 & الكلي & \\
\hline .56 & 2.63 & .50 & 3.01 & .45 & 2.62 & .69 & 2.50 & 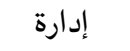 & خدمات \\
\hline .60 & 2.40 & .93 & 2.66 & .45 & 2.23 & .54 & 2.44 & مناهج & البيئة \\
\hline .59 & 2.52 & .73 & 2.85 & .49 & 2.43 & .57 & 2.47 & الكلي & الداخلية \\
\hline .60 & 2.61 & .54 & 2.89 & .46 & 2.60 & .69 & 2.50 & إدارة & خدمات \\
\hline .63 & 2.29 & .84 & 2.59 & .57 & 2.14 & .58 & 2.30 & مناهج & البيئة \\
\hline .63 & 2.46 & .69 & 2.76 & .56 & 2.38 & .64 & 2.41 & الكلي & الخارجية \\
\hline .58 & 2.78 & .42 & 3.31 & .36 & 2.73 & .64 & 2.61 & إدارة & \\
\hline .59 & 2.45 & .82 & 2.84 & .45 & 2.28 & .55 & 2.45 & مناهج & لأداة ككل \\
\hline .60 & 2.62 & .66 & 3.10 & .46 & 2.51 & .60 & 2.53 & الكلى & \\
\hline
\end{tabular}

الإحصائية للفروق، تم استخدام تحليل التباين الأحادي والمتعدد

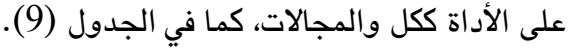

بالإشارة للنتائج الموضحة في الجدول (8) تبين أن هناك تباينا

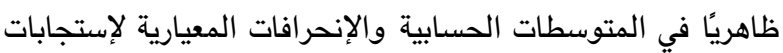

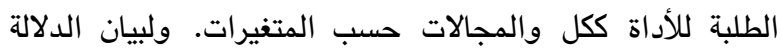

جدول (9): تحليل التباين الأحادي والمتعدد لمتوسطات الإستجابات للأداة ككل والمجالات حسب متغيرات التخصص والمستوى العلمي

و التفاعل بينها

\begin{tabular}{|c|c|c|c|c|c|c|}
\hline مستوى الدلالة & قيمة (ف) & متوسط المربعات & درجة الحرية & مجموع المربعات & مصدر التباين & المجالات \\
\hline .001 & 12.141 & 1.763 & 1 & 5.169 & \multirow{4}{*}{ الدلالة الإحصائية 0.107 الدصص 0.008} & العملية التعليمية \\
\hline .001 & 11.583 & 1.824 & 1 & 5.893 & & البحث العلمي \\
\hline .011 & 6.703 & 5.169 & 1 & 2.151 & & خدمات البيئة الداخلية \\
\hline .005 & 8.277 & 5.893 & 1 & 3.097 & & خدماكت البيئة الخارجية \\
\hline .000 & 16.245 & 2.151 & 2 & 13.833 & \multirow{4}{*}{$\begin{array}{c}\text { المستوى العلمي لامبادا } \\
0.766 \text { الدلادئة الإحصائية }\end{array}$} & العملية التعليمية \\
\hline .000 & 9.776 & 3.097 & 2 & 9.946 & & البحث العلمي \\
\hline .010 & 4.723 & 6.917 & 2 & 3.031 & & خدمات البيئة الداخلية \\
\hline .036 & 3.409 & 4.973 & 2 & 2.551 & & خدمات البيئة الخارجية \\
\hline .029 & 3.622 & 1.515 & 2 & 3.084 & \multirow{4}{*}{ العلمي لامبادا التصص المستوى 0.885} & العملية التعليمية \\
\hline .598 & .517 & 1.276 & 2 & .526 & & البحث العلمي \\
\hline .254 & 1.384 & 1.542 & 2 & .888 & & خدمات البيئة الداخلية \\
\hline .533 & .632 & .263 & 2 & .473 & & خدمات البيئة الخارجية \\
\hline & & .444 & 138 & 58.757 & \multirow{4}{*}{ الخطأ } & العملية التعليمية \\
\hline & & .236 & 138 & 70.204 & & البحث العلمي \\
\hline & & .426 & 138 & 44.273 & & خدمات البيئة الداخلية \\
\hline & & .509 & 138 & 51.638 & & خدمات البيئة الخارجية \\
\hline
\end{tabular}


حمزة

\begin{tabular}{|c|c|c|c|c|c|c|}
\hline مستوى الدلالة & قيمة (ف) & متوسط المربعات & درجة الحرية & مجموع المربعات & مصدر التباين & المجالات \\
\hline & & & 144 & 1255.471 & \multirow{4}{*}{ المجموع } & العملية التعليمية \\
\hline & & & 144 & 1113.704 & & البحث العلمي \\
\hline & & & 144 & 970.450 & & خدمات البيئة الداخلية \\
\hline & & & 144 & 931.827 & & خدمات البيئة الخارجية \\
\hline .000 & 12.946 & 3.928 & 1 & 3.928 & التخصص & \multirow{5}{*}{ الأداة ككل } \\
\hline .000 & 10.405 & 3.157 & 2 & 6.314 & المستوى العلمي & \\
\hline \multirow[t]{3}{*}{.272} & \multirow[t]{3}{*}{1.315} & .399 & 2 & .798 & التخصص*|المستوى & \\
\hline & & .303 & 138 & 41.868 & الخطأ & \\
\hline & & & 144 & 1048.533 & المجموع & \\
\hline
\end{tabular}

والأداة ككل. وبالنسبة للتفاعل بينهما: تبين وجود فروق ذات دلالة

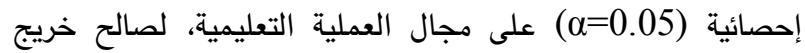

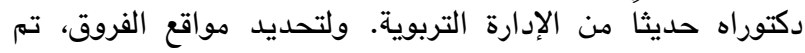

استخدام اختبار شيفيه للمقارنة البعدية كما في جدولة لترديل (10).
بالإشارة للنتائج الموضحة في الجدول (9)، لمتغير التخصص:

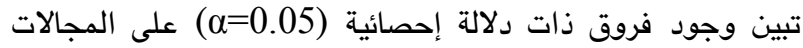
والأداة ككل بين متوسطي الإستجابات، لصالح طلبة الإدارة التربوية.

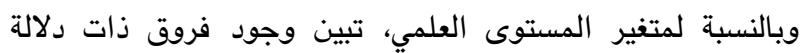

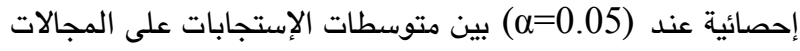

جدول (10): نتائج اختبار شيفيه للمقارنة البعدية لتحديد إتجاهات الفروق

\begin{tabular}{|c|c|c|c|c|}
\hline \multirow{2}{*}{ مستوى الدلالة } & \multirow{2}{*}{$\begin{array}{c}\text { فارق المتوسطات } \\
\text { J - I }\end{array}$} & \multicolumn{2}{|c|}{ المستوى العلمي } & \multirow{2}{*}{ مجالات الأداء الجامعي } \\
\hline & & $\mathrm{J}$ & I & \\
\hline 0.000 & .896 & طالب ماجستير & \multirow{10}{*}{ خريج دكتوراه حديث } & \multirow{2}{*}{ العملية التعليمية } \\
\hline 0.000 & .764 & طالب دكتوراه & & \\
\hline 0.001 & .653 & طالب ماجستير & & \multirow{2}{*}{ البحث العلمي } \\
\hline 0.000 & .795 & طالب دكتوراه & & \\
\hline 0.017 & .383 & طالب ماجستير & & \multirow{2}{*}{ الخدمات في البيئة الداخلية } \\
\hline 0.011 & .423 & طالب دكتوراه & & \\
\hline 0.049 & .353 & طالب ماجستير & & \multirow{2}{*}{ الخدمات في البيئة الخارجية } \\
\hline 0.043 & .381 & طالب دكتوراه & & \\
\hline 0.000 & .571 & طالب ماجستير & & \multirow{2}{*}{ الأداة ككل } \\
\hline 0.000 & .591 & طالب دكتوراه & & \\
\hline
\end{tabular}

نتائج السؤال الخامس: هل توجد علاقة ارتباطية بين مؤشرات

التخطيط الاستراتيجي والأداء الجامعي؟ تولي التئ

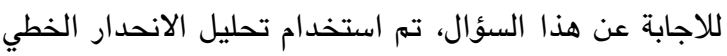

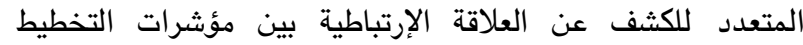

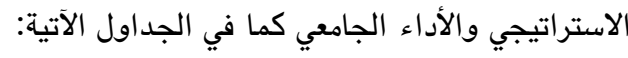

بالإشارة للنتائج الموضحة في الجدول (10) تبين أن مواقع الفروق على درجة الأداة ككل والمجالات جاءت لصاءة لصدالح خريج

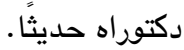


جدول (11): العلاقة الإرتباطية بين درجة توافر مجالات مؤشرات التخطيط الاستراتيجي ودرجة الأداء الجامعي

\begin{tabular}{|c|c|c|c|}
\hline معامل التحديد Re & معامل التحديد R2 & R R R R الارتباط & المتغيرات \\
\hline .664 & .673 & .821 & مجالات مؤشرات التخطيط \\
\hline
\end{tabular}

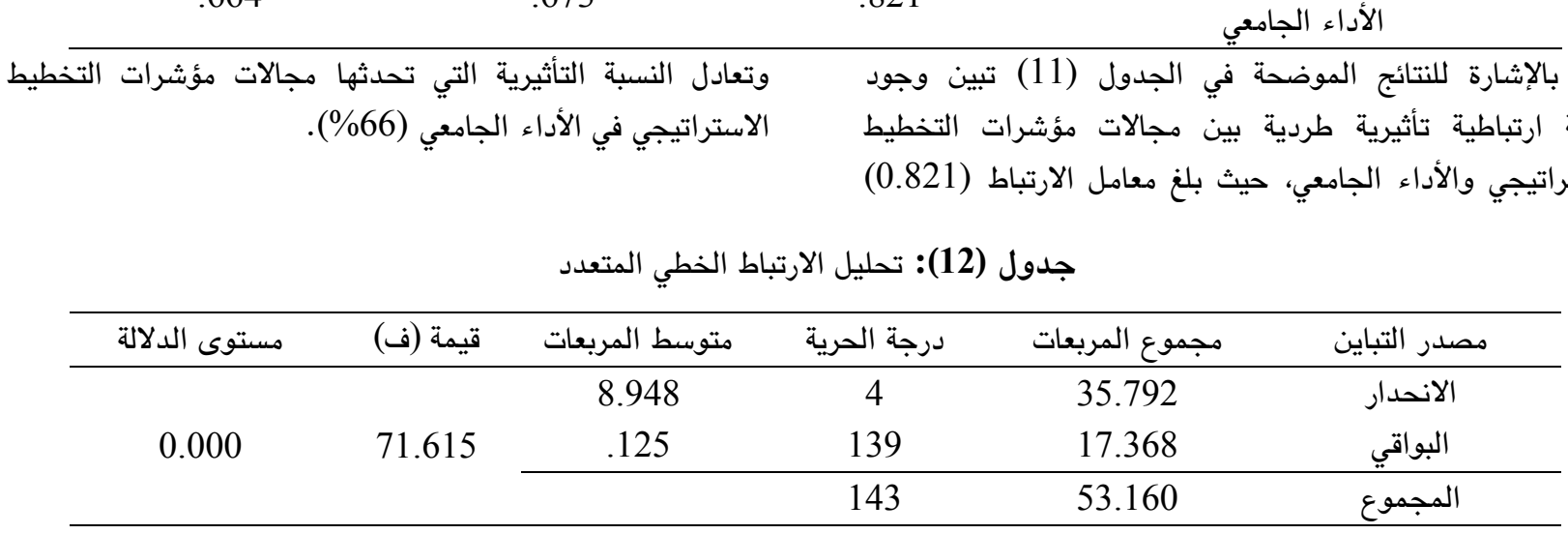

بالإشارة للنتائج الموضحة في الجدول (12) تبين وجود معنوية الدلالة الإحصائية للعلاقة الإرتباطية التأثيرية، حيث يتضح أن هذه العلاقة دالة إحصائيًا.

جدول (13): معاملات الانحدار الخطي المتعدد بين مجالات مؤشرات التخطيط الاستراتيجي والأداء الجامعي

\begin{tabular}{|c|c|c|c|c|c|c|}
\hline \multirow{2}{*}{ مستوى الدلالة } & \multirow{2}{*}{ قيمة (ت) } & \multirow{2}{*}{ معاملات الانحدار المعيارية } & \multicolumn{2}{|c|}{ معاملات الانحدار اللامعيارية } & \multirow{2}{*}{\multicolumn{2}{|c|}{ نموذج الانحدار }} \\
\hline & & & الخطأ المعياري & $\mathrm{B}$ & & \\
\hline 0.001 & 3.534 & - & 0.143 & 0.506 & ثابت الانحدار & \\
\hline 0.909 & -0.114 & -0.008 & 0.054 & -0.006 & القيم & 1 \\
\hline 0.712 & -0.370 & -0.034 & 0.073 & -0.027 & الرؤية & 2 \\
\hline 0.064 & 1.864 & 0.185 & 0.082 & 0.154 & 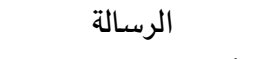 & 3 \\
\hline 0.000 & 7.840 & 0.693 & 0.084 & 0.657 & الأهداف الإستراتيجبة & 4 \\
\hline
\end{tabular}

Y معادلة الانحدار x

واضح على الواقع العملي. كما قدر الطلبة درجة توافر منخفضة لفقرة تمحورت حول سعي الجامعة إلى استثمار تكنولوجيا المعلومات والاتصال ويشكل مناسب، ويمكن عزو ذلك إلى إحتياج

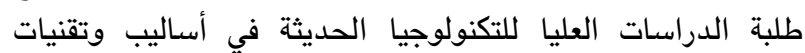

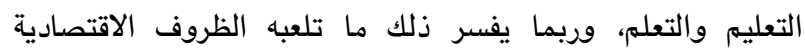

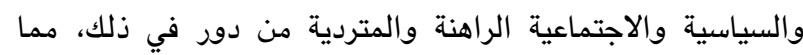
يؤثر في تحقيق جامعة عدن لأهدافها المنشودة. وتتفق هذه النتيجة مع دراسات خلصت إلى محدودية الإدراك

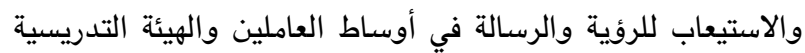

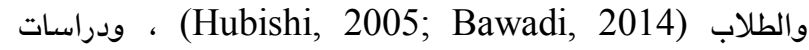
أكدت وجود ضعف في التخطيط الاستراتيجي، وعدم الإهتمام في

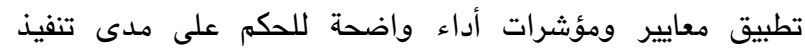
الخطط الاستراتيجية (Hubishi, 2005 ;Alobeidi, 2004)

.(Saeed, 2013 ;Kuliab, 2014
بالإشارة للنتائج الموضحة في الجدول (13)، تبين معاملات

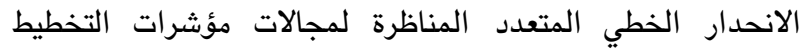
الاستراتيجي، حيث يبين معامل الانحدار الخطي لمجال الأهداف

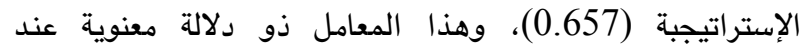
مستوى (0.05)، بينما جاءت معاملات الانحدار الخطي لمجالات

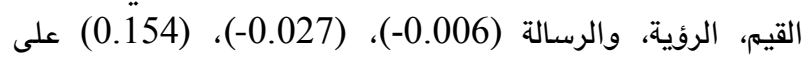

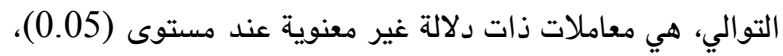

مناقشة النتائج

أظهرت نتائج السؤال الأول إدراك الطلبة لمؤشرات التخطيط

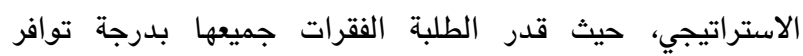
متوسطة، تؤكد المؤشرات على القيم التي ولدت السمعة الجيدة،

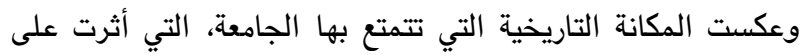
الجانبين القيمي والتربوي فيها؛ اللذين تتحدد من خلالهما الرؤية والرسالة والأهداف، إلا أن هذه المجالات بحاجة إلى التطبيق الفعلي الفي الفي

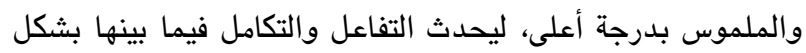


في البيئة الداخلية والخارجية بشكل خاص لا يحقق التطلعات في

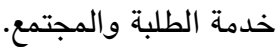
وأظهرت نتائج السؤال الخامس علاقة إرتباطية تأثيرية دالة بين

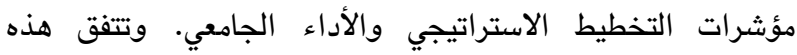

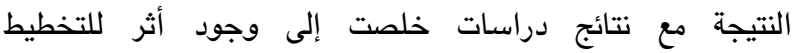

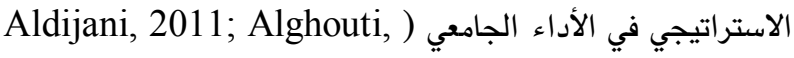
2017; AbdulRahman \& Alshuwaikh, 2015 إلى وجود دور إيجابي للتخطيط الاستراتيجي في تحسين الأداء.

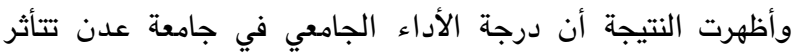

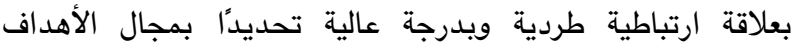

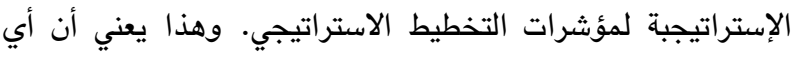
تغيير في درجة توافر مجال الأهداف الإستراتيجبة كمؤشر للتخطيط لإتيط

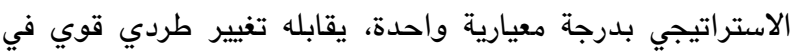

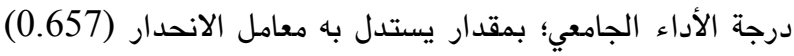

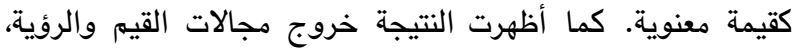
والرسالة من معادلة الانحدار في تفسير العلاقة الإرتباطية. ويفسر الإنية

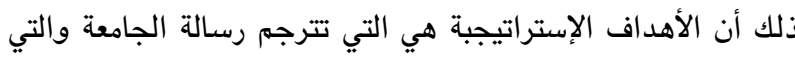

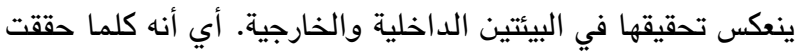

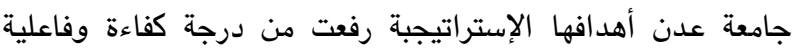
إنتاجية أدائها الجامعي.

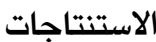

• ترتكز عملية التخطيط الاستراتيجي على القيم التي تستند إليها

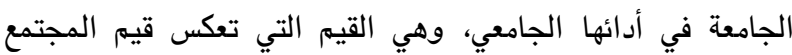
والتي حددت من خلالها الرؤية والرسالة والأهداف.

• عند إعداد الاستراتيجية، ينبغي إشراك الطلبة في صياغة أهدافها،

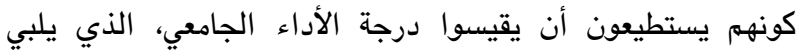
احتياجاتهم للاستفادة والاستمتاع بدراستهمه.

• التخطيط الاستراتيجي ومجالاته بحاجة للمراجعة والاهتمام

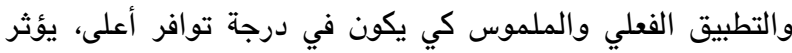

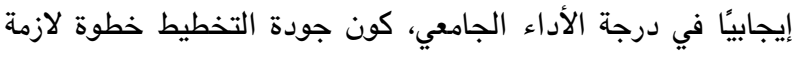
لتحقيق الجودة في الأداء ورفع الكفاءة الإنتاجية.

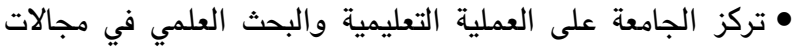

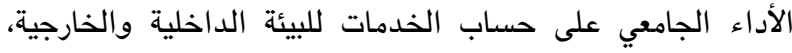
وهي بحاجة لإجراءات إصلاحية للتحسين. • ضعف الاهتمام بالتكنولوجيا وتقنياتها لتحقيق الأهداف الرامية لتنمية تعليم وتعلم الطلبة. • ضعف الموارد المالية والمادية وغياب المتابعة أضعف الخدمات

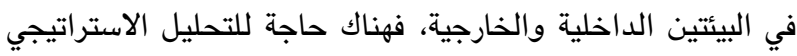

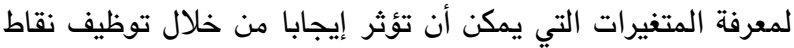
القوة واستثمار الفرص المتاحة لرفع درجة الأداء الجامعي.
كما أظهرت نتائج السؤال الثاني وجود فروق في مجالي

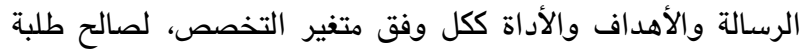

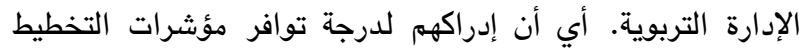

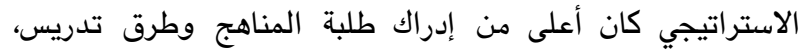

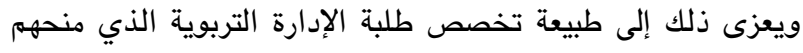

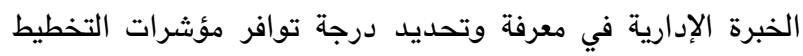
الاستراتيجي. ووفقا لمتغير المستوى العلمي، أظهرت النتيجة وجود

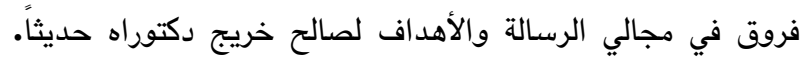

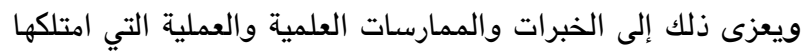

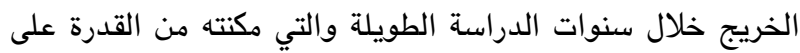
التمييز وتحديد درجة توافر مؤشرات التخطيط الاستراتيجي. أما الماليا

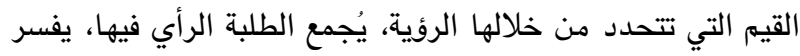
ذلك حرص جامعة عدن على نشر القيم بين طلبتها.

وأظهرت نتائج السؤال الثالث إدراك الطلبة لجميع مجالات

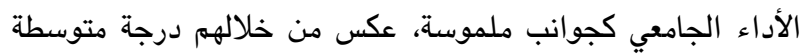

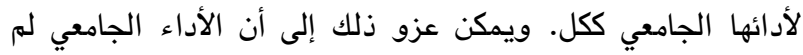

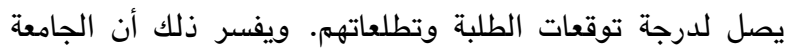

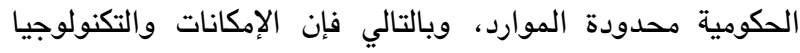

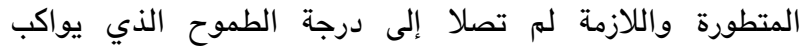

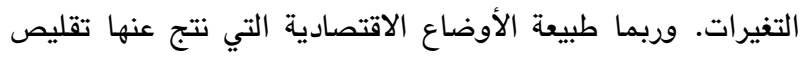

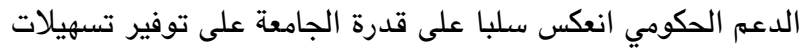

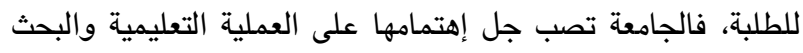

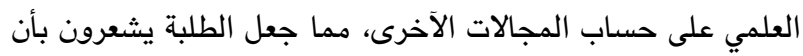

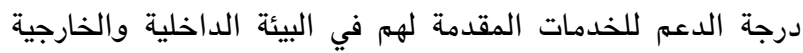

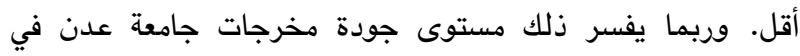

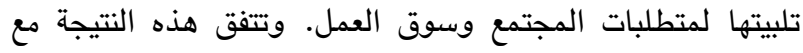

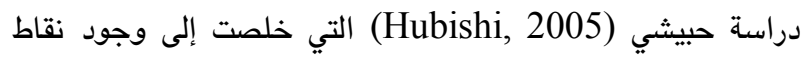

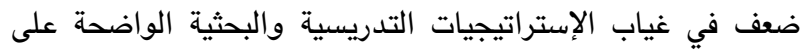

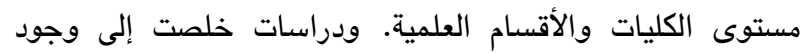

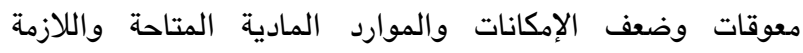
Cowburn, للتطوير التي أضعفت ممارسة التخطيط الاستراتيجية (2005;Murshid, 2004 ;Bawadi, 2008)

كما أظهرت نتائج السؤال الرابع وجود فروق في جميع

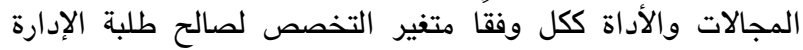

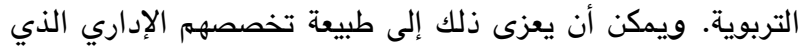

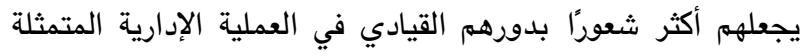

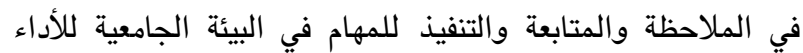

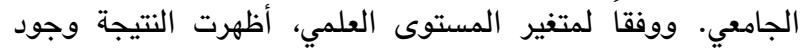

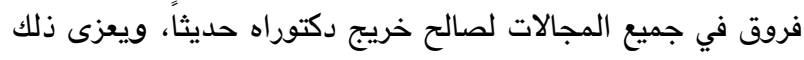

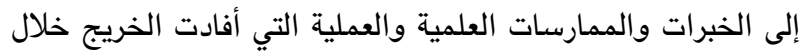

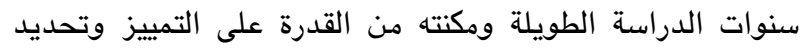

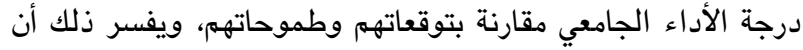
درجة الأداء الجامعي لجامعة عدن بشكل عام وما تقدمه من خدمات 


\section{References}

Abbas, S. (2006). Human resources management: A strategic approach. Amman: Dar Wael for Publication and Distribution.

AbdulRahman, R., \& Alshuwaikh, A. (2015). The role of strategic planning in improving overall performance Palestine Technical College- Dirr Albalah. Journal of Studies and Research, (20), 300-327.

Alabidi, A., \& Alabadi H. (2007). Using benchmarking in evaluation the university performance (comparative study between the faculty of management and economics / University of Kufa and the faculty of management and economics / University of Qadisiyah. Qadisiyah Journal of Science Administration and Economics, 9(3), 216-238.

Alaqeel, I., \& Alhyary, H. (2014). The role of the Jordanian Universities in supporting the values of citizenship. The Jordanian Journal of Educational Sciences ، 10(4), 517 -527

Aldawi, A. (2010). Analysis of the theoretical foundations of the concept of performance. Journal of Researcher ، 7, 217-227.

Aldijani, A. (2011). The role of strategic planning in the quality of the institutional performance: An analatical descriptive study in the Palestinian traditional universities. Doctoral Dissertation. University of Damascus, Syria. Retrieved from https://iugspace.iugaza.edu.ps /handle/20.500.12358/20284?

Alfayyad, S. (2004). Organizational culture, its source and dimensions. International Journal of Administrative Sciences, 9(1), 324-295.

Alghouti, M. (2017). The role of strategic planning in raising the productive efficiency of employees in higher education institutions in Gaza governorates. Master Thesis, Islamic University, Gaza. Retrieved from https:// iugspace.iugaza.edu.ps/handle/20.500.12358/1 7445.

Aljaradi, A. (2011). The role of strategic planning in raising the efficiency of the performance of Yemeni universities. Doctoral Dissertation. University of Halab, Syria.

Alkubaisi, A. (2006). Strategic planning for educational leaders. Journal of Naif Arab University for Security Science, 3(2), 22-60

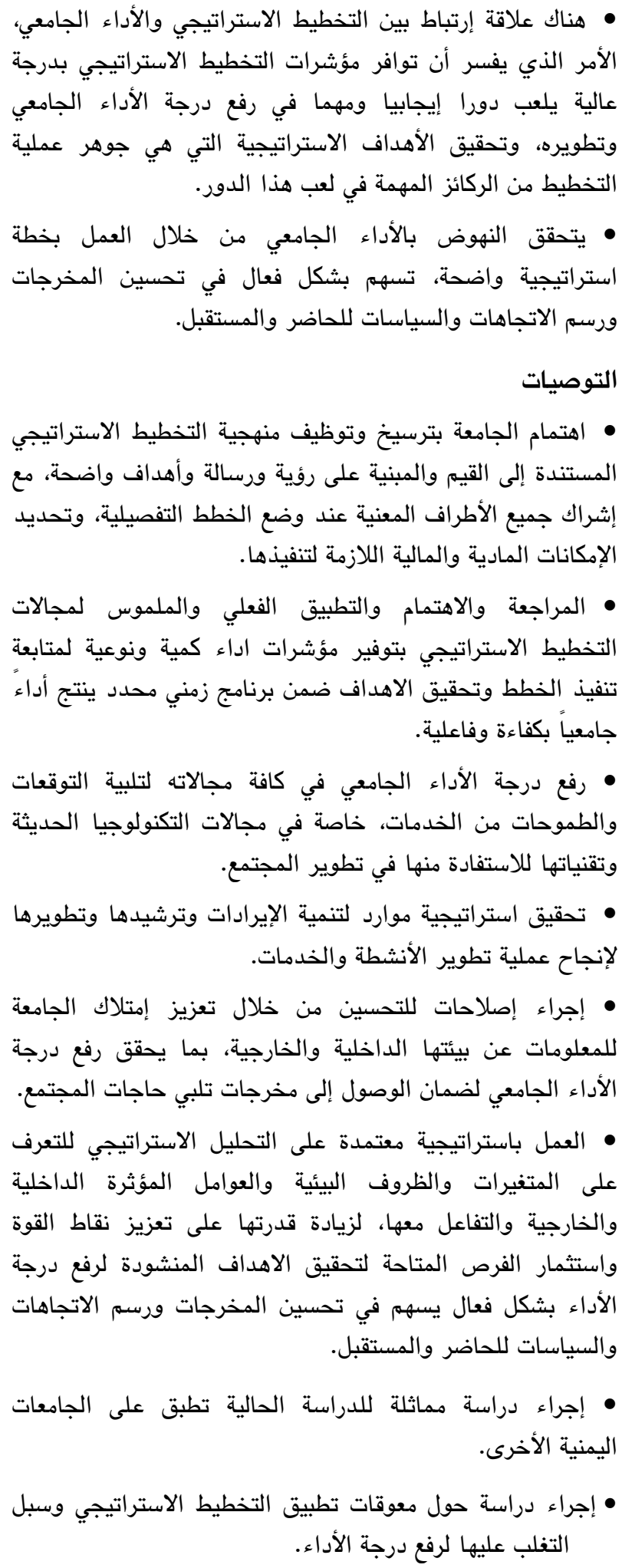


Alnakhi, M. (2010). Evaluation of the performance level of the postgraduate leading bodies of the University of Aden in the light of SWOT strategic analysis. Master Thesis. University of Aden, Yemen.

Alobeidi, C. (2004). Activate the role of Yemeni universities in achieving qualitative goals. Journal of Arts and Human Sciences, 5, 9-49.

Bawadi, S. (2008). Analysis of the internal environment and strategic planning components at Hadramout University. Master Thesis. University of Aden, Yemen.

Bawadi, S. (2014). A proposed framework for developing the quality of performance of the two faculties of education, (Aden, Mukalla), at Aden and Hadramout universities in the light of the assessment of administrative performance in accordance to the standards of performance excellence (Baldrige). Doctoral Dissertation. University of Aden, Yemen.

Bieler, A., \& McKenzie, M. (2017). Strategic planning for sustainability in Canadian higher education. Multidisciplinary Digital Publishing Institute, 9(2), 161-183.

Cowburn, S. (2005), Strategic planning in higher education: Fact or fiction?. Perspectives: Policy and Practices in Higher Education, 9(4), 103109.

Del Barrio, S., \& Luque, T. (2009). The value of client perception in university strategic planning: An empirical analysis study. Industry and Higher Education, 23(6), 423-436.

Druker, P. (1974). Management: Tasks, responsibilities, and practice. London: Hein Mann.

Gallagher. M. (2007). Improving institutional effectiveness: The relationship between assessing student learning outcomes and strategic planning in California Community College. Doctoral Dissertation. Claremont University، California.

Ghoneim, O. (2008). Planning foundations and general principles. Amman: Dar Safa for Publication and Distribution.

Hamza, A. (2012). The experience of higher education in the republic of Yemen in quality assurance and academic accreditation. The Arab Journal for Quality Assurance of University Education, 10, 43-60.

Hubishi, A. (2005). Strategic analysis for activating the role of the Yemeni university administration in achieving its aims. Master Thesis. University of Aden, Yemen.
Hussein A. (2001). Strategic leadership and its role in formulating the strategic direction of the university. Master Thesis. University of Aden, Yemen.

Kuliab, A. (2014). A proposed framework for developing the administrative performance of deans of colleges of education in Yemeni public universities. Master Thesis. University of Aden, Yemen.

Marzouqah, H. (2014). The impact of strategic planning of total quality management on employees' performance improvement of private universities in Jordan. Master Thesis. Middle East University, Lebanon. Retrieved from https://meu.edu.jo/libraryTheses/58625 e4c3ab0c_1.pdf

Ministry of Higher Education and Scientific Research. (2006). The national strategy for higher education in the Republic of Yemen and the future action plan (2006-2010). Retrieved from.

Murshid, F. (2004). Factors affecting the effectiveness of performance in Yemeni universities. Master Thesis. University of Sana'a, Yemen.

Obaidat, D., Abdul-Haq, K., \& Adas, A. (2004). Scientific research: Its concept and methods of its methodologies. Amman: Dar El Fakir for Printing and Publishing.

Rabaya, F. (2011). Reference benchmarking for improving institutional performance in public organizations: An applied study to the Supreme Council for Science and Technology. Mu'tah University Journal, 26(7), 109-164.

Rustam, R. (2004). Strategic planning in university education. Journal of Quality in Higher Education,1(1), 61-79

Saeed, F. (2013). The reality of strategic planning at the University of Aden in light of the requirements of total quality manageme. Master Thesis. University of Aden, Yemen.

Wheelen, T., \& Hunger, J. (2004). Essentials of strategic managemant. ( $3^{\text {rd }}$ ed.). New Jersey: Prentice Hall.

Zoabi, R. (2014). Impact of strategic planning on the performance of Algerian higher education institutions (from balanced score card perspective:. A case study of the University of Mohammed Khiedr Biskra. Master Thesis. University of Mohamed Khader, Algeria. Retrieved from https://www.mobt3ath.com /uplode/book/book-4133.pdf. 